\title{
Role of Cannabidiol in the Therapeutic Intervention for Substance Use Disorders
}

\author{
Francisco Navarrete ${ }^{1,2}$, María Salud García-Gutiérrez ${ }^{1,2}$, Ani Gasparyan ${ }^{1,2}$, \\ Amaya Austrich-Olivares ${ }^{1}$ and Jorge Manzanares ${ }^{1,2 *}$
}

${ }^{1}$ Instituto de Neurociencias, Universidad Miguel Hernández-CSIC, San Juan de Alicante, Spain, ${ }^{2}$ Red Temática de Investigación Cooperativa en Salud (RETICS), Red de Trastornos Adictivos, Instituto de Salud Carlos III, MICINN and FEDER, Madrid, Spain

\section{OPEN ACCESS}

Edited by:

Luis F Callado,

University of the Basque Country,

Spain

Reviewed by:

Styliani (Stella) Vlachou,

Dublin City University, Ireland

F. Markus Leweke,

The University of Sydney, Australia

Olga Valverde,

Pompeu Fabra University, Spain

${ }^{*}$ Correspondence:

Jorge Manzanares

jmanzanares@umh.es

Specialty section: This article was submitted to

Neuropharmacology,

a section of the journal

Frontiers in Pharmacology

Received: 04 November 2020

Accepted: 04 May 2021

Published: 20 May 2021

Citation:

Navarrete F, García-Gutiérrez MS, Gasparyan A, Austrich-Olivares A and

Manzanares J (2021) Role of

Cannabidiol in the Therapeutic Intervention for Substance

Use Disorders.

Front. Pharmacol. 12:626010.

doi: 10.3389/fphar.2021.626010
Drug treatments available for the management of substance use disorders (SUD) present multiple limitations in efficacy, lack of approved treatments or alarming relapse rates. These facts hamper the clinical outcome and the quality of life of the patients supporting the importance to develop new pharmacological agents. Lately, several reports suggest that cannabidiol (CBD) presents beneficial effects relevant for the management of neurological disorders such as epilepsy, multiple sclerosis, Parkinson's, or Alzheimer's diseases. Furthermore, there is a large body of evidence pointing out that CBD improves cognition, neurogenesis and presents anxiolytic, antidepressant, antipsychotic, and neuroprotective effects suggesting potential usefulness for the treatment of neuropsychiatric diseases and SUD. Here we review preclinical and clinical reports regarding the effects of $\mathrm{CBD}$ on the regulation of the reinforcing, motivational and withdrawal-related effects of different drugs of abuse such as alcohol, opioids (morphine, heroin), cannabinoids, nicotine, and psychostimulants (cocaine, amphetamine). Furthermore, a special section of the review is focused on the neurobiological mechanisms that might be underlying the 'anti-addictive' action of CBD through the regulation of dopaminergic, opioidergic, serotonergic, and endocannabinoid systems as well as hippocampal neurogenesis. The multimodal pharmacological profile described for $\mathrm{CBD}$ and the specific regulation of addictive behavior-related targets

\footnotetext{
Abbreviations: 2-AG, 2-arachidonoylglycerol; 3H-DAMGO, D-Ala ${ }^{2}$, NMePhe ${ }^{4}$, Gly ol; 5HT1a, serotonin 1a receptor; 5HTT, serotonin transporter; AEA, anandamide; Amy, amygdala; AMPA, a-amino-3-hydroxy-5-methyl-4-isoxazolepropionic acid receptor; AUD, alcohol use disorder; BDNF, brain-derived neurotrophic factor; BPN, buprenorphine; CB1R, cannabinoid receptor 1; CB2R, cannabinoid receptor $2 \mathrm{CBD}$, cannabidiol; $\mathrm{CBT}$, cognitive behavioral therapy; CNS, central nervous system; $\mathrm{CPA}$, conditioned place aversion; CPP, conditioned place preference; CREB, cAMP response element-binding protein; CUD, cannabis use disorder; DAGL, diacylglycerol; DALYs, disability-adjusted life years; DAT, dopamine transporter; DG, dentate gyrus; DR, dorsal raphe; DSM-5, diagnostic and statistical manual of mental disorders, 5th version; ECS, endocannabinoid system; EMA, European Medicines Agency; EtOH, Ethanol; FAAH, fatty acid amide hydrolase; FDA, Food and Drug Administration; FR1, fixed-ratio 1; FR3, fixed-ratio 3; FMRI, functional Magnetic Resonance Imaging; GPCRs, Gq protein-coupled receptors; Glu, glutamate; HIPP, hippocampus; ICD-11, International Classification of Diseases; ICSS, intracranial selfstimulation; ICV, intracerebroventricular; MAGL, monoacylglycerol lipase; MAPK, mitogen-activated protein kinase; MET, motivational enhancement therapy; MOr, mu-opioid receptor; NAcc, nucleus accumbens; NAPE-PLD, N-acylphosphatidylethanolamine specific phospholipase D; NMDAr, N-methyl-d-aspartate receptors; NTX, naltrexone; OUD, opioid use disorder; PFC, prefrontal cortex; PTSD, post-traumatic stress disorder; RCT, randomized controlled trial; RT-PCR, real time polymerase chain reaction; SA, self-administration; SUD, substance use disorder; SVZ, subventricular zone; THC, delta-9tetrahydrocannabinol; THC-COOH, 11-nor-9-carboxy- $\delta$-9-tetrahydrocannabinol; TH, tyrosine hydroxylase; TNF- $\alpha$, tumor necrosis factor $\alpha$; VEC, voluntary ethanol consumption; VTA, ventral tegmental area; YLDs, years lived with disability.
} 
explains, at least in part, its therapeutic effects on the regulation of the reinforcing and motivational properties of different drugs of abuse. Moreover, the remarkable safety profile of $\mathrm{CBD}$, its lack of reinforcing properties and the existence of approved medications containing this compound (Sative ${ }^{\circledR}$, Epidiole ${ }^{\circledR}$ ) increased the number of studies suggesting the potential of $\mathrm{CBD}$ as a therapeutic intervention for SUD. The rising number of publications with substantial results on the valuable therapeutic innovation of CBD for treating SUD, the undeniable need of new therapeutic agents to improve the clinical outcome of patients with SUD, and the upcoming clinical trials involving CBD endorse the relevance of this review.

\section{Keywords: cannabidiol, substance use disorder, alcohol, cocaine, cannabis, psychostimulant, neurobiology}

\section{INTRODUCTION}

Substance Use Disorders (SUD) are chronic and relapsing clinical conditions meeting the diagnostic criteria for drug dependence defined by the Diagnostic and Statistical Manual of Mental Disorders (DSM-5) (APA, 2013) and the World Health Organization's International Classification of Diseases (ICD11) (World Health Organization, 2018). SUD are one of the most important health problems globally. In 2017, it was estimated that over 30 million individuals present an SUD leading to more than 31 thousand years lived with disability (YLDs) with a worrying increase (16.7\%) over the previous decade (GBD 2017 Disease and Injury Incidence and Prevalence Collaborators, 2018). Furthermore, substance use was indirectly and directly responsible for 11.8 million deaths which implies one in five deaths worldwide (GBD 2017 Disease and Injury Incidence and Prevalence Collaborators, 2018).

Despite the range of the psychosocial and pharmacological therapeutic approaches for substance use treatment, relapse prevalence into drug consumption is estimated between 40 and 75\% (Sinha, 2011; Pasareanu et al., 2016; Andersson et al., 2019). This high rate of recurrence is largely due to the ineffectiveness of the available drugs or the lack of specific treatments (e.g., cannabis, cocaine, or amphetamine-type use disorders). Thus, there is a growing need to significantly improve our knowledge about the underlying mechanisms involved in the development of drug dependence to finally design new pharmacological tools with higher efficacy and safety. In this sense, the manipulation of the endocannabinoid system (ECS) by administering cannabinoid compounds has raised much interest due to its close functional involvement in the regulation of emotion, cognition, and reward (Solinas et al., 2008; Marco et al., 2011; Campolongo and Trezza, 2012; Marco and Laviola, 2012; Manzanares et al., 2018; Navarrete et al., 2020).

Cannabis sativa plant contains numerous chemical entities including cannabinoids, terpenes, and phenolic compounds (Andre et al., 2016). To date, over 120 cannabinoids have been isolated from the plant (Morales et al., 2017). From these, delta-9tetrahydrocannabinol (THC) is the main psychotomimetic or hallucinogenic component and the first cannabinoid to be identified and studied. First described and synthesized by Roger Adams in 1942 (Adams, 1942), and then isolated for the first time by Gaoni and Mechoulam in 1964 (Gaoni and
Mechoulam, 1964), THC mediates the rewarding properties of cannabis (Zhang et al., 2004). Along with THC, cannabidiol (CBD) is the other most abundant phytocannabinoid in the Cannabis sativa plant. It was first synthesized by Roger Adams (Adams, 1942) and isolated by Mechoulam and Shvo in 1963 (Mechoulam et al., 1963), from which a growing interest in its pharmacological actions began to emerge. The results from basic and clinical studies suggested that CBD may present beneficial effects for the management of neurological disorders such as epilepsy (Carlini and Cunha, 1981; Devinsky et al., 2014; Devinsky et al., 2016), multiple sclerosis (Kozela et al., 2011; Giacoppo et al., 2015; Jones and Vlachou, 2020), Parkinson's (Zuardi et al., 2009; Chagas et al., 2014) or Alzheimer's diseases (Martín-Moreno et al., 2011; Cheng et al., 2014). Moreover, there is a growing body of evidence suggesting that CBD improves cognition (Osborne et al., 2016) and neurogenesis (Liput et al., 2013; Schiavon et al., 2016), and presents antipsychotic (Zuardi et al., 1991; Moreira and Guimarães, 2005; Long et al., 2006; Leweke et al., 2012; Leweke et al., 2016; Peres et al., 2016), anxiolytic (Guimarães et al., 1990; Moreira et al., 2006; Resstel et al., 2006; Blessing et al., 2015) and antidepressant-like effects (Zanelati et al., 2010; Linge et al., 2016; Sartim et al., 2016). All these potential therapeutic actions of $\mathrm{CBD}$ are due to its multiple pharmacological mechanisms. CBD was proposed to directly or indirectly modulate the function of more than 65 targets in the central nervous system (CNS) (Ibeas Bih et al., 2015), including cannabinoid receptors (CB1, CB2), GPR55 receptor, vanilloid receptor TRPV1, serotonin 5HT1a receptor (Bisogno et al., 2001; Russo et al., 2005; Ryberg et al., 2007; Thomas et al., 2007; Campos et al., 2012), the anandamide (AEA) hydrolyzing enzyme (fatty acid amide hydrolase, FAAH) or the adenosine transporter (Carrier et al., 2006; Massi et al., 2008). However, additional studies are needed to precisely determine the target engagement profile of CBD.

Importantly, CBD lacks addictive potential in contrast to THC. Several studies in animals and humans demonstrated the absence of rewarding properties (Parker et al., 2004; Katsidoni et al., 2013; Babalonis et al., 2017; Schoedel et al., 2018). Indeed, recent studies carried out in mice in our laboratory further demonstrate that CBD is not an addictive substance. A range of $\mathrm{CBD}$ doses were evaluated in different animal models of addiction commonly used to assess the reinforcing and motivational properties of drugs (conditioned place preference 
(CPP) and oral self-administration (SA)). Also, withdrawalrelated signs were analyzed after the abrupt cessation of CBD chronic administration. Interestingly, CBD did not induce CPP, oral SA or withdrawal-related signs, findings that suggested the lack of rewarding effects of CBD (Viudez-Martínez et al., 2019). Moreover, CBD presents an excellent safety profile supported by both animal and clinical studies (Bergamaschi et al., 2011; Iffland and Grotenhermen, 2017; Taylor et al., 2018). Proof of this is the recent marketing of the drug Epidiolex ${ }^{\circledR}$, a $99 \%$ pure oral CBD extract for the treatment of refractory childhood epilepsies (Lennox-Gastaut and Dravet syndrome) (Sekar and Pack, 2019; Raucci et al., 2020). Likewise, nabiximols is another marketed formulation containing $\mathrm{CBD}$ and THC (25 and $27 \mathrm{mg} / \mathrm{ml}$, respectively) under the trade name Sativex ${ }^{\circledR}$. Nabiximols is an oromucosal spray widely employed for the treatment of muscle spasticity in multiple sclerosis patients (Patti et al., 2016; Giacoppo et al., 2017).

Therefore, the versatile pharmacological profile and safety of CBD support its therapeutic potential in the management of SUD. This review focuses on collecting all the available evidence about the effects of CBD on the different aspects that accompany drug dependence (reinforcement, motivation, contextual conditioning, relapse, withdrawal syndrome or motor sensitization). Also, it covers all the mechanisms proposed to mediate the CBD actions on drug addiction.

\section{METHODS}

The literature review consisted of an exhaustive search for scientific information in the Medline database (PubMed). A total of 7 search boxes were employed according to the total of drugs included in the review: cannabis, alcohol, morphine, heroin, amphetamine/methamphetamine, cocaine, and nicotine. These terms were combined with the term "cannabidiol" by the Boolean operator "AND". All the results for each search were critically analyzed by all the authors to decide the selection of each reference according to the adequacy of its content with the subject matter of the study. No PubMed filters were applied to maximize the selection of all the available and appropriate information. All original articles, systematic reviews or meta-analyses focusing on the effects of $\mathrm{CBD}$ on drug addiction were accepted. Those articles not related to the topic of interest, not written in English or to which access was not possible were discarded. In addition, the same searches were performed on the ClinicalTrials.gov database to retrieve all the ongoing clinical studies.

\section{CBD AS A POTENTIAL NEW PHARMACOLOGICAL TOOL FOR THE TREATMENT OF SUD}

This section details all the available evidence, both pre-clinical and clinical, about the therapeutic potential of CBD in the management of various SUD.

\section{CBD and Cannabis}

Cannabis is the second smoked substance of abuse after tobacco (Hasin et al., 2016) and the most consumed illicit drug worldwide (World Drug Report, 2020). The use of cannabis is growing due to the increasing legalization trend for medicinal and recreational purposes. Furthermore, according to recent studies, THC concentrations in cannabis doubled in the past decade and consequently the content of CBD substantially dropped to an almost non-detectable level (Chandra et al., 2019; Freeman et al., 2019). This scenario facilitates cannabis consumption and may lead to the development of dependence criteria in the context of cannabis use disorder (CUD), affecting approximately 22 million people (Degenhardt et al., 2018). CUD is associated with disruptions in social, occupational, recreational activities and mental health problems. The latter includes impaired cognition abilities and motor coordination, euphoria, depression, psychosis, dependence and withdrawal syndrome (Patel and Marwaha, 2020). Although not medically serious, cannabis withdrawal should be a focus of treatment because one-half of the patients in treatment for CUD report withdrawal-related symptoms and it may serve as a negative reinforcement for relapse to cannabis use in individuals trying to abstain (Budney and Hughes, 2006; Levin et al., 2010; Gorelick et al., 2012).

Nowadays there is no official drug approved for the treatment of CUD by the main drug regulatory authorities (i.e., European Medicine Agency (EMA) or US Food and Drug Administration (FDA)). Many studies were carried out to find out new pharmacotherapies with two main aims: 1) to identify medications to attenuate symptoms of cannabis withdrawal, and 2) to identify medications to reduce subjective and reinforcing effects of cannabis. Some off-label pharmacological interventions targeting distinct neurotransmitter systems involved in drug dependence were investigated (for a recent review see (Sabioni and Le Foll, 2019; Brezing and Levin, 2018)). Recently, the pharmacological modulation of the cannabinoid system gained great interest as a potential therapeutic approach for CUD. Particularly, in the last years CBD attracted much attention as a pharmacological tool for the treatment of CUD due to its safety and multimodal pharmacological profile (García-Gutiérrez et al., 2018) (Table 1). Also, it has been proposed that CBD may reduce the negative psychotropic effects of THC (for a recent review see (Niesink and van Laar, 2013; Freeman et al., 2019)) and might potentiate its positive therapeutic actions (Russo and Guy, 2006; McPartland and Russo, 2014).

Several studies carried out with cannabis users classified them according to the higher or lower CBD:THC ratio of their smoked cannabis. Interestingly, CBD reduces the rewarding effects of THC since cannabis smokers $(n=94)$ with high CBD:THC ratio showed reduced attentional bias to drug stimuli and lower selfrated liking of cannabis (Morgan et al., 2010). Another study recruited cannabis users $(n=134)$ that were classified based on levels of CBD in their own chosen cannabis, low (0.14\%) vs. high (0.75\%). CBD-enriched cannabis did not cause the deficits of immediate and delayed prose recall that were caused by $\mathrm{CBD}$ poor cannabis (Morgan et al., 2010), and users habitually exposed 
TABLE 1 | Main findings from human and animal studies aimed to evaluate the therapeutic potential of CBD for the treatment of cannabis use disorder.

\begin{tabular}{|c|c|c|c|c|c|}
\hline \multicolumn{6}{|c|}{ CBD and cannabis } \\
\hline Treatment & $\begin{array}{l}\text { Doses, route } \\
\text { of administration, } \\
\text { and treatment } \\
\text { duration }\end{array}$ & Study design/model & $\begin{array}{l}\text { Subjects, samples, } \\
\text { and gender }\end{array}$ & Main outcomes & References \\
\hline \multicolumn{6}{|l|}{ Clinical studies } \\
\hline $\begin{array}{l}\text { Nabiximols } \\
\text { (CBD:THC) }\end{array}$ & $\begin{array}{l}80 \text { mg CBD:84.6 mg THC/day } \\
\text { (maximum daily doses), oromucosal } \\
\text { spray, } 6 \text { days }\end{array}$ & $\begin{array}{l}\text { 2-Site, inpatient, } \\
\text { double-blind RCT }\end{array}$ & $\begin{array}{l}\text { Cannabis-dependent treatment } \\
\text { seekers } N=51 \text { ( } 39 \mathrm{M} \text { and } 12 \mathrm{~F} \text { ) }\end{array}$ & $\begin{array}{l}\downarrow \text { CWS } \\
=\text { Weekly cannabis use } \\
\uparrow \text { withdrawal treatment } \\
\text { retention }\end{array}$ & Allsop et al. (2014) \\
\hline $\begin{array}{l}\text { Sativex } \\
\text { (CBD:THC) }\end{array}$ & $\begin{array}{l}100 \text { mg CBD: } 108 \text { mg THC/day } \\
\text { (maximum daily doses), oromucosal } \\
\text { spray, } 8 \text { weeks }\end{array}$ & $\begin{array}{l}\text { Double-blind placebo- } \\
\text { controlled trial }\end{array}$ & $\begin{array}{l}\text { Community-recruited cannabis } \\
\text { dependent patients } N=9(8 \mathrm{M} \\
\text { and } 1 \mathrm{~F})\end{array}$ & $\begin{array}{l}\downarrow \text { CWS } \\
=\text { Craving }\end{array}$ & Trigo et al. (2016) \\
\hline $\begin{array}{l}\text { Sativex } \\
\text { (CBD:THC) } \\
+ \text { MET/CBT }\end{array}$ & $\begin{array}{l}105 \text { mg CBD: } 113,4 \text { mg THC/day } \\
\text { (maximum daily doses), oromucosal } \\
\text { spray, } 12 \text { weeks }\end{array}$ & Open-label trial & $\begin{array}{l}\text { Treatment-seeking community- } \\
\text { recruited cannabis-dependent } \\
\text { patients } N=4(2 \mathrm{M} \text { and } 2 \mathrm{~F})\end{array}$ & $\begin{array}{l}\downarrow \text { cannabis use } \\
=\text { CWS }\end{array}$ & Trigo et al. (2016) \\
\hline $\begin{array}{l}\text { Nabiximols } \\
\text { (CBD/THC) }\end{array}$ & $\begin{array}{l}100 \text { mg CBD:108 mg THC/day, } \\
\text { oromucosal spray, } 8 \text { weeks }\end{array}$ & Double-blind RCT & $\begin{array}{l}\text { Treatment-seeking cannabis- } \\
\text { dependent patients } N=40(29 \mathrm{M} \\
\text { and } 11 \mathrm{~F})\end{array}$ & $\begin{array}{l}\downarrow \text { cannabis use } \\
\downarrow \text { craving } \\
=\text { CWS }\end{array}$ & Trigo et al. (2018) \\
\hline $\begin{array}{l}\text { Nabiximols } \\
\text { (CBD/THC) } \\
+ \text { CBT }\end{array}$ & $\begin{array}{l}80 \text { mg CBD: } 86,4 \text { mg THC/day } \\
\text { (maximum daily doses), oromucosal } \\
\text { spray, } 12 \text { weeks }\end{array}$ & $\begin{array}{l}\text { Multi-site, outpatient, } \\
\text { double-blind RCT }\end{array}$ & $\begin{array}{l}\text { Treatment-seeking cannabis- } \\
\text { dependent patients } N=128(98 \mathrm{M} \\
\text { and } 30 \mathrm{~F})\end{array}$ & $\begin{array}{l}\downarrow \text { cannabis use } \\
=\text { Craving } \\
=\text { CWS }\end{array}$ & $\begin{array}{l}\text { Bhardwaj et al. (2018); } \\
\text { Lintzeris et al. (2019) }\end{array}$ \\
\hline CBD & $\begin{array}{l}300-600 \text { mg/day, capsules, p.o., } \\
11 \text { days }\end{array}$ & Case report & $\begin{array}{l}19 \text { years-old } F \text { with cannabis } \\
\text { dependence }\end{array}$ & $\begin{array}{l}\downarrow \text { CWS } \\
\downarrow \text { frequency of relapse }\end{array}$ & Crippa et al. (2013) \\
\hline CBD & $\begin{array}{l}18-24 \mathrm{mg} / \text { day, oromucosal spray, } \\
5 \text { months }\end{array}$ & Case report & $\begin{array}{l}27 \text { years-old } \mathrm{M} \text { with bipolar } \\
\text { disorder and cannabis } \\
\text { dependence }\end{array}$ & $\begin{array}{l}\downarrow \text { anxiety levels } \\
\downarrow \text { sleep disturbances } \\
\text { Cessation of cannabis use }\end{array}$ & $\begin{array}{l}\text { Shannon \& } \\
\text { Opila-Lehman (2015) }\end{array}$ \\
\hline CBD & $\begin{array}{l}0,200,400,800 \mathrm{mg} / \text { day, capsules, } \\
\text { p.o., } 8 \text { outpatient sessions }\end{array}$ & $\begin{array}{l}\text { Multi-site, double- } \\
\text { blind, within- } \\
\text { subject RCT }\end{array}$ & $\begin{array}{l}\text { Non-treatment seeking healthy } \\
\text { cannabis users } N=31 \text { (17 M } \\
\text { and } 14 \mathrm{~F})\end{array}$ & $\begin{array}{l}=\text { Cannabis self- } \\
\text { administration } \\
=\text { Subjective effects } \\
=\text { Cannabis ratings }\end{array}$ & Haney et al. (2016) \\
\hline CBD & $\begin{array}{l}\text { 0, } 200,400,800 \mathrm{mg} / \text { day, capsules, } \\
\text { p.o., } 4 \text { weeks }\end{array}$ & $\begin{array}{l}\text { Phase } 2 \mathrm{a} \text {, double- } \\
\text { blind RCT }\end{array}$ & $\begin{array}{l}\text { Participants meeting CUD criteria } \\
N=82(59 \mathrm{M} \text { and } 23 \mathrm{~F})\end{array}$ & $\begin{array}{l}\downarrow \text { cannabis use } \\
\downarrow \text { urinary } \mathrm{THC}-\mathrm{COOH}: \\
\text { creatinine ratio }\end{array}$ & Freeman et al. (2020) \\
\hline CBD & $\begin{array}{l}200 \text { mg/day, capsules, p.o., } \\
10 \text { weeks }\end{array}$ & Open-label trial & $\begin{array}{l}\text { Regular cannabis users } N=18 \\
(14 \mathrm{M} \text { and } 4 \mathrm{~F})\end{array}$ & $\begin{array}{l}\downarrow \text { cannabis-induced } \\
\text { hippocampal } \\
\text { disturbances }\end{array}$ & Beale et al. (2018) \\
\hline CBD & $\begin{array}{l}200 \text { mg/day, capsules, p.o., } \\
10 \text { weeks }\end{array}$ & Open-label trial & Regular cannabis users $N=16(\mathrm{M})$ & $\begin{array}{l}\downarrow \text { cannabis-induced } \\
\text { euphoria } \\
\downarrow \text { depressive and } \\
\text { psychotic-like symptoms } \\
\uparrow \text { attentional switching, } \\
\text { verbal learning, and } \\
\text { memory }\end{array}$ & Solowij et al. (2018) \\
\hline Epidiolex (CBD) & $\begin{array}{l}800 \text { mg/day (maximum daily dose), } \\
\text { solution, p.o., } 6 \text { weeks }\end{array}$ & Double-blind RCT & $\begin{array}{l}\text { Cannabis-dependent patients } N= \\
10(4 \mathrm{M} \text { and } 6 \mathrm{~F})\end{array}$ & $\uparrow$ cannabis use & $\begin{array}{l}\text { ClinicalTrials.gov ID: } \\
\text { NCT03102918 }\end{array}$ \\
\hline CBD & $\begin{array}{l}300-600 \text { mg/day, capsules, p.o., } \\
6 \text { weeks }\end{array}$ & Double-blind RCT & $\begin{array}{l}\text { Patients with psychosis and } \\
\text { cannabis abuse } N=130 \text { (M/F) }\end{array}$ & $\begin{array}{l}\text { - Cannabis cessation } \\
\text { - Psychotic symptoms (no } \\
\text { results posted yet) }\end{array}$ & $\begin{array}{l}\text { ClinicalTrials.gov ID: } \\
\text { NCT04105231 }\end{array}$ \\
\hline CBD & 600 mg/day, p.o., 12 weeks & Double-blind RCT & $\begin{array}{l}\text { Regular cannabis users with } \\
\text { recent-onset psychosis } N=84 \\
\text { (M/F) }\end{array}$ & $\begin{array}{l}\text { - Change in BPRS score } \\
\text { - Change in MATRICS } \\
\text { score } \\
\text { - Change in serum [THC- } \\
\text { COOH] (no results } \\
\text { posted yet) }\end{array}$ & $\begin{array}{l}\text { ClinicalTrials.gov ID: } \\
\text { NCT03883360 }\end{array}$ \\
\hline \multicolumn{6}{|l|}{ Animal studies } \\
\hline CBD & 5, 10, 30 mg/kg, i.p., acute treatment & $\begin{array}{l}\text { Spontaneous } \\
\text { cannabinoid } \\
\text { withdrawal }\end{array}$ & C57BL/6J mice $N=180(\mathrm{M})$ & $\begin{array}{l}\downarrow \text { anxiety level } \\
\downarrow \text { hyperactivity } \\
\downarrow \text { withdrawal somatic } \\
\text { signs }\end{array}$ & Navarrete et al. (2018) \\
\hline CBD & 0-20 mg/kg, i.p., chronic treatment & $\begin{array}{l}\text { Precipitated } \\
\text { cannabinoid } \\
\text { withdrawal }\end{array}$ & C57BL/6J mice $N=335(\mathrm{M})$ & $\begin{array}{l}=\text { Withdrawal somatic } \\
\text { signs } \\
\downarrow \text { anxiety level }\end{array}$ & Myers et al. (2019) \\
\hline
\end{tabular}

CBD, cannabidiol; THC, tetrahydrocannabinol; RCT, randomized clinical trial; CWS, cannabis withdrawal syndrome; MET, motivational enhancement therapy; CBT, cognitive behavioral therapy; BPRS, Brief Psychiatric Rating Scale; MATRICS, MATRICS Consensus Cognitive Battery; CUD, cannabis use disorder; M, male; F, female; p.o., per os (oral administration); i.p., intraperitoneal injection; $\uparrow$, increase; $\downarrow$, decrease; =, no effect. 
to $\mathrm{CBD}$-rich cannabis relatively preserved recognition memory vs. CBD-poor cannabis users (Morgan et al., 2012). Likewise, the analysis of cannabinoids in hair samples collected from 140 individuals allowed the comparison between "THC only", "THC + CBD" and "no cannabinoid" groups in terms of schizophrenia-like symptoms. The "THC + CBD" group showed lower levels of positive psychotic symptoms compared with the "THC only" and "no cannabinoid" groups (Morgan and Curran, 2008). These findings are relevant for the therapeutic and public health implications, suggesting that for recreational cannabis users and for those patients taking medicinal cannabis, a more balanced CBD to THC concentration would improve therapeutic endpoints while minimizing side effects.

In a recent clinical trial with healthy volunteers $(n=17)$ experienced with cannabis (not regular users), functional Magnetic Resonance Imaging (fMRI) studies were performed to investigate the effects of THC (8 mg) and THC + CBD (8 mg + $10 \mathrm{mg}$ ) on resting-state brain functional connectivity. CBD restored the THC-induced disruption of the salience network, effect that authors associated with its potential to treat disorders of salience such as psychosis and addiction (Wall et al., 2019). Likewise, another study enrolling frequent and infrequent cannabis users $(n=36)$ evaluated the effects of THC alone (8 mg) and THC combined with low (4 mg) or high (400 mg) doses of CBD. The results showed that only the high dose of CBD reduced the intoxicating effects of THC (Solowij et al., 2019). In addition, the cannabinoid spray Sativex (1:1 ratio of CBD:THC) at low doses reduces some of the effects produced by THC, including subjective ratings of intoxication and abuse/ dependence (Robson, 2011; Schoedel et al., 2011). Also, CBD: THC (1:1 or 1:10 ratios) reversed the conditioned place aversion (CPA) induced by the acute injection of THC (10 mg/kg) in Long Evans rats (Vann et al., 2008).

The protective effects of CBD alone on THC-induced impairments were extensively explored in preclinical and clinical studies. For instance, the administration of CBD $(0.5 \mathrm{mg} / \mathrm{kg})$ to rhesus monkeys challenged with THC $(0.2$, $0.5 \mathrm{mg} / \mathrm{kg}$ ) significantly attenuated THC-induced cognitive disturbances (Wright Jr. et al., 2013). CBD reduced anxiety and improved fear-related responses induced by THC in male Sprague Dawley rats via a bidirectional control of ERK1-2 phosphorylation (Hudson et al., 2019). In C57BL/6J mice, CBD (3 mg/kg) significantly blunted the cognitive alterations induced by THC $(1 \mathrm{mg} / \mathrm{kg})$ administration in an object recognition task (Aso et al., 2019). In the clinical setting, CBD $(1 \mathrm{mg} / \mathrm{kg})$ blocked the anxiety induced by THC $(0.5 \mathrm{mg} / \mathrm{kg})$ (Zuardi et al., 1982). Furthermore, CBD pre-treatment $(600 \mathrm{mg})$ inhibited THC $(1.5 \mathrm{mg})$-induced paranoia, inhibited the detrimental effects of THC on episodic memory and decreased the proportion of participants experiencing clinically significant acute THC psychosis (Englund et al., 2013). Importantly, the restorative properties of $\mathrm{CBD}$ were also explored in 18 regular cannabis users (heavy and light users) enrolled in a 10 weeks open-label pragmatic trial. Authors measured baseline and post-CBD hippocampal subregions volumes by structural fMRI. CBD restored cannabis-induced anatomical disturbances in the subicular and CA1 subfields of the hippocampus (HIPP) in current cannabis users, especially in those with greater lifetime exposure (Beale et al., 2018). In the same study, CBD improved psychological symptoms (depressive and psychotic-like traits) and cognition (attentional switching, verbal learning, and memory) in dependent cannabis users (Solowij et al., 2018).

Considering the significant CBD-mediated attenuation of the negative outcomes induced by THC, as well as the promising effects of cannabinoid agonist substitution approaches employing synthetic derivatives of THC (e.g., dronabinol, nabilone) (Haney et al., 2004; Budney et al., 2007; Haney et al., 2008; Haney et al., 2013; Vandrey et al., 2013), there has been a growing interest in the therapeutic potential of the combination CBD:THC for the treatment of distinct aspects of CUD (Allsop et al., 2015). Cannabis-dependent treatment seekers $(n=51)$ received nabiximols (maximum daily doses: $80 \mathrm{mg} \mathrm{CBD/86.4} \mathrm{mg} \mathrm{THC,}$ oromucosal spray) or placebo with standardized psychosocial interventions. Nabiximols significantly reduced the severity of cannabis withdrawal and prolonged the retention in withdrawal treatment (Allsop et al., 2014). Later, Trigo et al. first explored the effects of fixed or self-titrated dosages of Sativex (maximum daily doses: $100 \mathrm{mg}$ CBD:108 mg THC, oromucosal spray) on cannabis withdrawal and craving. High fixed Sativex doses were well tolerated and significantly attenuated cannabis withdrawal while craving was similar compared to placebo (Trigo et al., 2016). Second, the effects of self-titrated Sativex doses combined with motivational enhancement therapy and cognitive behavioral therapy (MET/CBT) on cannabis withdrawal, use and craving were evaluated. Self-titrated Sativex (maximum daily doses: $105 \mathrm{mg}$ CBD/113.4 mg of THC, oromucosal spray) with MET/ CBT significantly decreased cannabis use and prevented cannabis withdrawal under abstinence conditions in these case series (Trigo et al., 2016). Third, the same previous experimental design was employed to evaluate the tolerability, safety, and efficacy of nabiximols (maximum daily doses: $100 \mathrm{mg}$ CBD: $108 \mathrm{mg}$ THC, oromucosal spray). Cannabis use as well as craving were reduced in nabiximols-treated patients compared with placebo, although no differences were found on withdrawal scores (Trigo et al., 2018). Finally, a clinical trial examined the safety and efficacy of nabiximols treatment (up to 32 oromucosal sprays containing $86.4 \mathrm{mg} \mathrm{THC} / 80 \mathrm{mg} \mathrm{CBD}$ ), combined with individual CBT (Bhardwaj et al., 2018). Interestingly, the nabiximols group reported significantly less days using cannabis than the placebo group while both groups improved to a comparable degree on a range of secondary cannabis-related and general health and psychosocial outcomes (Lintzeris et al., 2019).

One of the major concerns of the cannabinoid replacement therapy is whether the presence of THC in nabiximols could be problematic, especially in the still unexplored long-term treatment of CUD. For this reason, special attention has been paid to the evaluation of the clinical efficacy of CBD alone. The potential therapeutic usefulness of CBD for the treatment of CUD was investigated in some case report clinical studies. Crippa et al. administered CBD for 11 days (300 mg on day 1, $600 \mathrm{mg}$ on days $2-10$, and $300 \mathrm{mg}$ on day 11 , capsules, p.o.) to a 19 year-old female with cannabis dependence who experienced withdrawal 
syndrome when she tried to cease cannabis use. Daily assessments showed a rapid decrease in withdrawal symptoms leading to a score of zero in all tests by day 6. A 6 months follow-up showed a relapse in cannabis use but at a lower frequency (once or twice a week vs. 7 days a week) (Crippa et al., 2013). Another case report study evaluated the use of a CBD oil in a 27 year-old male presenting a long-standing diagnosis of bipolar disorder and a daily addiction to cannabis use. After initiating the treatment with CBD oil (18-24 mg/day, oromucosal spray), the patient reported a decrease in the anxiety level and sleep disturbances, as well as a complete cessation of cannabis use (Shannon and Opila-Lehman, 2015). A multi-site clinical study analyzed the effects of oral CBD $(0,200,400,800 \mathrm{mg}$, capsules, p.o.) on the reinforcing, subjective, cognitive, and physiological effects of smoked cannabis. CBD was administered 90 min prior to smoking half of a cannabis cigarette by non-treatment-seeking healthy cannabis users $(n=31)$ during 8 outpatient sessions. No difference was found in comparison with placebo-treated patients (Haney et al., 2016). This may be due to the acute CBD treatment, the study population (nontreatment-seeking patients) or the poor bioavailability of oral CBD. Recently, a phase $2 \mathrm{a}$, double-blind, placebo-controlled, randomized clinical trial was carried out to identify efficacious doses of CBD (200, 400 and $800 \mathrm{mg}$, capsules, p.o., 4 weeks) for the treatment of CUD. Following a 2-stages design with 82 participants meeting CUD criteria from DSM-5 (48 in stage 1 and 34 in stage 2), CBD efficacy was determined according to urinary 11-nor-9-carboxy- $\delta$-9-tetrahydrocannabinol (THC$\mathrm{COOH})$ :creatinine ratio and/or increased days per week with abstinence from cannabis during treatment. CBD 400 and $800 \mathrm{mg}$ doses were well tolerated and more efficacious than placebo at reducing cannabis use (Freeman et al., 2020). Another recent clinical study also explored the effects of CBD (Epidiolex, up to $800 \mathrm{mg}$, solution, p.o., 6 weeks treatment period) in cannabis dependent subjects $(n=10)$. Although no significant differences were found, cannabis consumption was higher in the CBDtreated group. However, as stated by the authors, more participants are necessary to draw definitive conclusions from this study (Clinicaltrials.gov identifier: NCT03102918). Interestingly, two clinical trials have been recently registered (Clinicaltrials.gov identifiers: NCT04105231 and NCT03883360) to explore the effects of long-term administration of CBD (up to $600 \mathrm{mg}$, capsules, p.o., 6 or 12 weeks, respectively) on psychiatric symptoms, cognition, and cannabis consumption in patients with recent-onset psychosis and comorbid cannabis use.

Apart from the valuable information provided by clinical studies, it is essential to analyze the effects of CBD on behavioral and neurobiological alterations related with cannabis dependence at the preclinical level. For that purpose, our laboratory was the first to explore CBD actions (5, 10 and $20 \mathrm{mg} / \mathrm{kg}$, i.p.) in an animal model of spontaneous cannabinoid withdrawal syndrome developed after 7 days of treatment with CP-55,940 (a 45-fold more potent cannabinoid 1 receptor (CB1R) agonist compared to THC) (Aracil-Fernández et al., 2013). Withdrawal-related behavioral signs were evaluated by measuring motor activity, somatic signs, and anxiety-like behavior in abstinent $\mathrm{C} 57 \mathrm{BL} / 6 \mathrm{~J}$ mice treated with $\mathrm{CBD}$ or its corresponding vehicle. In addition, real-time PCR (RT-PCR) analyses were performed to evaluate changes in the gene expression of relevant targets of the cannabinoid, dopaminergic, and opioidergic systems. Interestingly, CBD administration significantly blocked the increase in motoractivity, number of rearings, rubbings, and jumpings associated with spontaneous cannabinoid withdrawal, and normalized the decrease in the number of groomings. Furthermore, the anxiogenic-like effect observed in abstinent mice was completely abolished by CBD. These effects were associated with a CBD-induced up-regulation of tyrosine hydroxylase $(\mathrm{TH})$ in the ventral tegmental area (VTA) and cannabinoid 2 receptor $(\mathrm{CB} 2 \mathrm{R})$ in the nucleus accumbens (NAcc), whereas a down-regulation of mu-opioid receptor (MOR) and CB1R in the NAcc (Navarrete et al., 2018). Also, a recent study was aimed to evaluate if CBD $(0-20 \mathrm{mg} / \mathrm{kg}$, i.p. $)$ improves cognitive deficits and withdrawal signs induced by cannabinoid CB1/CB2 receptor agonists such as THC. CB1R antagonist (SR141716) administration precipitated withdrawal signs in chronically THC-treated C57BL/6J mice and they were not attenuated by CBD. However, the lack of CBD-induced withdrawal signs or cognitive performance impairment, together with the robust anxiolytic effect led the authors to conclude that $\mathrm{CBD}$ as a monotherapy might be a safer pharmacological agent for the treatment of several disorders (Myers et al., 2019).

According to the previous evidence, it seems that $\mathrm{CBD}$ could play a crucial role in the management of CUD. The clinical studies that are underway as well as future investigations will be decisive to determine the therapeutic application of CBD to treat cannabis addiction.

\section{CBD and Alcohol}

Problematic alcohol use is an important risk factor for many health problems significantly contributing to the global burden of disease (Collaborators, 2018). In 2016, harmful alcohol use caused 3 million of deaths worldwide and 132.6 million disability-adjusted life years (DALYs) (OMS, 2019). Alcohol Use Disorder (AUD) is one of the most common addictive disorders with a greatest health and socioeconomic impact. The prevalence of AUD varies from 13 to $30 \%$ in most western countries (Grant et al., 2015; WHO, 2018). Current options for AUD treatment are scarce and have limited efficacy. To date, there are only four drug-based treatments approved for AUD by the FDA and EMA: naltrexone, nalmefene, acamprosate, and disulfiram (Soyka and Müller, 2017). Despite the optimization of pharmacological and psychosocial interventions for the management of AUD, at least $60 \%$ of alcoholic patients usually relapse during the first 6 months after dishabituation treatment (Maisto et al., 2006; Kirshenbaum et al., 2009; Witkiewitz, 2011; Durazzo and Meyerhoff, 2017). Thus, the need for new pharmacological approaches proving higher efficacy in alcohol relapse avoidance and maintenance of abstinence is evident. In this sense, CBD has recently attracted attention because of its ability to modulate the reinforcing and motivational effects of alcohol, as well as to improve the damage produced by alcohol in 
TABLE 2 | Main findings from clinical and animal studies aimed to evaluate the therapeutic potential of CBD for the treatment of alcohol use disorder.

\begin{tabular}{|c|c|c|c|c|c|}
\hline \multicolumn{6}{|c|}{ CBD and alcohol } \\
\hline Treatment & $\begin{array}{l}\text { Doses, route } \\
\text { of administration, } \\
\text { and treatment } \\
\text { duration }\end{array}$ & $\begin{array}{l}\text { Study design/ } \\
\text { model }\end{array}$ & $\begin{array}{l}\text { Subjects, samples, } \\
\text { and gender }\end{array}$ & Main outcomes & References \\
\hline \multicolumn{6}{|c|}{ Clinical studies } \\
\hline CBD & 600 and 1,200 mg/day, p.o., $4+4$ weeks & Double-blind RCT & $\begin{array}{l}\text { Patients with moderate } \\
\text { or severe AUD (DSM-5) } \\
N=40(\mathrm{M} / \mathrm{F})\end{array}$ & $\begin{array}{l}\text { - TLFB assessment of alcohol } \\
\text { consumption in serum } \\
\text { - Change in \% CDT assessment of } \\
\text { alcohol consumption in serum (no } \\
\text { results posted yet) }\end{array}$ & $\begin{array}{l}\text { ClinicalTrials.gov ID: } \\
\text { NCT03252756 }\end{array}$ \\
\hline CBD & 600 mg/day, p.o., 6 weeks & Double-blind RCT & $\begin{array}{l}\text { Patients with AUD and } \\
\text { PTSD comorbidity } N= \\
48(\mathrm{M} / \mathrm{F})\end{array}$ & $\begin{array}{l}\text { - Number of drinks per day with } \\
\text { TLFB (no results posted yet) }\end{array}$ & $\begin{array}{l}\text { ClinicalTrials.gov ID: } \\
\text { NCT03248167 }\end{array}$ \\
\hline CBD & $\begin{array}{l}800-1,200 \text { mg/day, capsules, p.o., } \\
4 \text { days }\end{array}$ & Double-blind RCT & $\begin{array}{l}\text { Patients with AUD } \\
\text { undergoing alcohol } \\
\text { withdrawal } N=52(\mathrm{M} / \mathrm{F})\end{array}$ & $\begin{array}{l}\text { - diazepam use over the } 5 \text { days } \\
\text { withdrawal period (no results } \\
\text { posted yet) }\end{array}$ & $\begin{array}{l}\text { ClinicalTrials.gov ID: } \\
\text { NCT04205682 }\end{array}$ \\
\hline \multicolumn{6}{|c|}{ Animal studies } \\
\hline CBD & $\begin{array}{l}\text { 30, } 60,120 \mathrm{mg} / \mathrm{kg} \text {, i.p., } 30 \mathrm{mg} / \mathrm{kg} / \text { day, } \\
\text { s.c. (continuous controlled release), } \\
\text { chronic treatment }\end{array}$ & VC, ESA & $\begin{array}{l}\text { C57BL/6J mice } N= \\
40(\mathrm{M})\end{array}$ & $\begin{array}{l}\downarrow \text { ethanol intake and preference } \\
\downarrow \text { motivation to ethanol } \\
\text { consumption } \\
\downarrow \text { ethanol relapse }\end{array}$ & $\begin{array}{l}\text { Viudez-Martínez et al. } \\
\text { (2018a) }\end{array}$ \\
\hline CBD & 15 mg/kg/day, t.d., 7 days & ESA, DRT & Wistar rats $N=52(\mathrm{M})$ & $\begin{array}{l}\downarrow \text { context-induced and stress- } \\
\text { induced reinstatement } \\
\downarrow \text { impulsivity level in rats with alcohol } \\
\text { dependence history }\end{array}$ & $\begin{array}{l}\text { Gonzalez-Cuevas } \\
\text { et al. (2018) }\end{array}$ \\
\hline $\begin{array}{c}\mathrm{CBD} \\
\mathrm{CBD}+\mathrm{THC}\end{array}$ & $\begin{array}{l}2.5 \mathrm{mg} / \mathrm{kg} \mathrm{CBD} \pm 2.5 \mathrm{mg} \mathrm{THC} \text {, i.p., acute } \\
\text { treatment }\end{array}$ & $\begin{array}{l}\text { Ethanol-induced } \\
\text { locomotor } \\
\text { sensitization }\end{array}$ & DBA 2 mice $N=84(M)$ & $\downarrow$ motor sensitization to ethanol & Filev et al. (2017) \\
\hline $\begin{array}{l}\text { CBD } \pm N T X \\
\text { WAY }\end{array}$ & $\begin{array}{l}20 \text { mg/kg/day CBD, s.c. (continuous } \\
\text { controlled release) } \pm 0.7 \text { mg/kg NTX; p.o., } \\
0.3 \text { mg/kg WAY, i.p., chronic treatment }\end{array}$ & ESA & $\begin{array}{l}\text { C57BL/6J mice } N= \\
140(\mathrm{M})\end{array}$ & $\begin{array}{l}\downarrow \text { motivation to ethanol } \\
\text { consumption (CBD }+ \text { NTX) } \rightarrow \\
\text { abolished by WAY }\end{array}$ & $\begin{array}{l}\text { Viudez-Martínez et al. } \\
\text { (2018b) }\end{array}$ \\
\hline CBD & $\begin{array}{l}15,30,60,90 \mathrm{mg} / \mathrm{kg} \text {, i.p., chronic } \\
\text { treatment }\end{array}$ & Binge drinking & $\begin{array}{l}\text { C57BL/6J mice } N=120 \\
(60 \mathrm{M} \text { and } 60 \mathrm{~F})\end{array}$ & $\begin{array}{l}\downarrow \text { ethanol intake ( } 30,60 \text { and } \\
90 \mathrm{mg} / \mathrm{kg} \text {, repeated } \\
\text { administration, M) } \\
\downarrow \text { ethanol intake ( } 90 \mathrm{mg} / \mathrm{kg} \text {, acute } \\
\text { and repeated administration, F) }\end{array}$ & $\begin{array}{l}\text { Viudez-Martínez et al. } \\
\text { (2020) }\end{array}$ \\
\hline CBD & 20, 40 mg/kg, i.p., repeated treatment & $\begin{array}{l}\text { Binge ethanol } \\
\text { exposure }\end{array}$ & Sprague-dawley rats (M) & $\begin{array}{l}\downarrow \text { ethanol-induced hippocampal and } \\
\text { entorhinal cortical } \\
\text { neurodegeneration }\end{array}$ & Hamelink et al. (2005) \\
\hline CBD & $\begin{array}{l}1,1.0,2.5 \text { and } 5.0 \% \text { gel, t.d., } 40 \text { mg } / \mathrm{kg} \text {, } \\
\text { i.p., repeated treatment }\end{array}$ & $\begin{array}{l}\text { Binge ethanol } \\
\text { exposure }\end{array}$ & Sprague-dawley rats (M) & $\downarrow F J B+$ cells in the entorhinal cortex & Liput et al. (2013) \\
\hline CBD & $5 \mathrm{mg} / \mathrm{kg}$, i.p., 5 days & $\begin{array}{l}\text { Binge ethanol } \\
\text { exposure }\end{array}$ & C57BL/6J mice (M) & $\begin{array}{l}\uparrow \text { alcohol-induced liver steatosis } \\
\downarrow \text { alcohol-mediated oxidative stress } \\
\downarrow \text { JNK MAPK activation } \\
\uparrow \text { autophagy }\end{array}$ & Yang et al. (2014) \\
\hline CBD & $5,10 \mathrm{mg} / \mathrm{kg}$, i.p., 11 days & $\begin{array}{l}\text { Chronic ethanol } \\
\text { exposure }\end{array}$ & C57BL/6J mice (M) & $\begin{array}{l}\downarrow \text { alcohol feeding-induced serum } \\
\text { transaminase elevations } \\
\downarrow \text { hepatic inflammation } \\
\downarrow \text { oxidative/nitrative stress }\end{array}$ & Wang et al. (2017) \\
\hline
\end{tabular}

CBD, cannabidiol; THC, tetrahydrocannabinol; RCT, randomized clinical trial; AUD, alcohol use disorder; DSM-5, Diagnostic and Statistical Manual of Mental Disorders; TLFB, Time-line Follow-back scale; CDT, carbohydrate deficient transferrin; VC, voluntary consumption; ESA, ethanol self-administration; DRT, delayed reinforcement task; WAY, WAY-100635 (5HT1a selective antagonist); M, male; F, female; p.o., per os (oral administration); i.p., intraperitoneal injection; t.d., transdermal; $\uparrow$, increase; $\downarrow$, decrease; = , no effect.

the liver or CNS (De Ternay et al., 2019; Turna et al., 2019) (Table 2).

Our laboratory was the first to publish relevant data regarding the effects of CBD on ethanol reinforcement, motivation, and relapse in $\mathrm{C} 57 \mathrm{BL} / 6 \mathrm{~J}$ male mice. Voluntary ethanol consumption (VEC) and oral ethanol SA procedures were employed. First, VEC was evaluated in a two-bottle choice paradigm in which mice were repeatedly administered with different doses of CBD
(30, 60 and $120 \mathrm{mg} / \mathrm{kg}$, i.p.). Ethanol consumption and preference were significantly reduced by CBD in a dose-dependent manner. Second, oral ethanol SA was carried out in operant skinner boxes to evaluate the effects of a single administration of CBD in a microparticle formulation providing a constant release $(30 \mathrm{mg} / \mathrm{kg} /$ day, s.c.). Interestingly, CBD significantly reduced the number of active lever presses and ethanol intake under fixed-ratio 1 (FR1) and fixed-ratio 3 (FR3) schedules, as well as 
the breaking point that measures the motivation to drink alcohol. Third, the effects of CBD on alcohol relapse were also analyzed in the oral ethanol SA paradigm with some modifications. The administration of CBD (120 mg/kg, i.p.) significantly reduced the number of active lever presses and ethanol intake during relapsing conditions. Importantly, these effects were accompanied by changes on the relative gene expression (RTPCR) of selected dopaminergic, opioidergic and cannabinoid targets. Briefly, CBD induced a down-regulation of $\mathrm{TH}$ in the VTA and MOR, CB1R and G-protein coupled receptor 55 (GPR55) gene expressions in the NAcc whereas CB2R mRNA levels were increased in the NAcc (Viudez-Martínez et al., 2018a). Shortly thereafter, Gonzalez-Cuevas et al. demonstrated that CBD transdermal administration (fast-drying 2.5\% hydroalcoholic gel formulation, $15 \mathrm{mg} / \mathrm{kg} /$ day, 7 days) significantly attenuated the context- and stress-induced reinstatement for ethanol seeking, and this effect lasted up to 5 months. In addition, CBD fully reversed the high impulsivity level showed by rats with an EtOH dependence history (Gonzalez-Cuevas et al., 2018). On the other hand, the effects of CBD alone or in combination with THC $(2.5 \mathrm{mg} / \mathrm{kg}$ each, i.p., 4 days) on ethanol-induced locomotor sensitization were also evaluated in DBA/ 2 mice. THC alone or combined with CBD, but not $\mathrm{CBD}$ alone, significantly inhibited the expression of sensitization to ethanol in this paradigm (Filev et al., 2017).

The combination of different drugs is a commonly used procedure for the treatment of AUD. This strategy usually provides a greater effect and prevents certain dose-related side effects by using lower doses of each drug than the ones employed in monotherapy. Taking into consideration this approximation, our group was also aimed to explore whether the combination of CBD with naltrexone (NTX) might reduce alcohol consumption and motivation to drink in $\mathrm{C} 57 \mathrm{BL} / 6 \mathrm{~J}$ mice to a higher extent. For that purpose, the effects of a sub-effective dose of NTX ( $0.7 \mathrm{mg} / \mathrm{kg}$, p.o.), CBD $(20 \mathrm{mg} / \mathrm{kg} /$ day, s.c., microparticles formulation for continuous controlled release for 3 weeks) or their combination were evaluated. Interestingly, the administration of CBD plus NTX was the only treatment able to reduce motivation and ethanol intake in the oral ethanol SA. Also, these effects were associated with a down-regulation in the gene expression of $\mathrm{TH}$ in the VTA, MOR in the NAcc, and serotonin 1a receptor (5HT1a) in the dorsal raphe. To elucidate the role of 5HT1a receptors in the mechanisms that could underlie CBD plus NTX effects on ethanol reinforcement and motivation, the 5HT1a antagonist WAY 100635 was concomitantly administered. Pretreatment with this compound significantly blocked the effects of CBD plus NTX, a finding that supports the involvement of 5HT1a receptors (ViudezMartínez et al., 2018a).

One of the major concerns of harmful ethanol consumption is the binge drinking pattern that has become a major public health problem in modern societies (Lannoy et al., 2019). Nevertheless, the available pharmacological options for binge drinking management are scarce and limited (Rolland and Naassila, 2017). In this respect, therapeutic usefulness of CBD for the treatment of binge drinking patterns was analyzed also by our group taking into consideration gender differences. The effects of $\mathrm{CBD}$ on ethanol binge drinking were explored in male and female C57BL/6J mice by using the drinking in the dark procedure. Repeated CBD administration (15, 30 and $60 \mathrm{mg} / \mathrm{kg}$, i.p.) significantly reduced ethanol intake only in males and was associated with a down-regulation of $\mathrm{TH}$ gene expression in the VTA, and MOR and CB1R gene expressions in the NAcc. Interestingly, a higher $\mathrm{CBD}$ dose $(90 \mathrm{mg} / \mathrm{kg}$, i.p.) significantly reduced ethanol intake under acute and repeated administration patterns not only in males but also in females (Viudez-Martínez et al., 2020). Except for these findings, previous studies provided evidence of $\mathrm{CBD}$ neuroprotective actions in rodent models of ethanol binge intoxication. In 2005, Hamelink et al. demonstrated that $\mathrm{CBD}(40 \mathrm{mg} / \mathrm{kg}$, i.p.) significantly reduced the number of degenerated argyrophilic neurons in the dentate gyrus of the HIPP and the entorhinal cortex of Sprague Dawley rats exposed to a 4 days ethanol binge administration (Hamelink et al., 2005). Also, Liput and cols followed a similar procedure showing a significant CBD-mediated reduction in the neurodegeneration induced by ethanol binge treatment reflected in a lower number of Fluoro-Jade B positive cells in the entorhinal cortex (Liput et al., 2013). Finally, it is worth to mention that CBD might also present protective actions against alcohol-induced liver disease, attenuating hepatic steatosis and metabolic dysregulation by antiinflammatory and antioxidant mechanisms in animal models of repeated ethanol exposure (Yang et al., 2014; Wang et al., 2017).

Taking into consideration the promising preclinical data pointing out $\mathrm{CBD}$ as a potential therapeutic tool for AUD, clinical studies were recently initiated. In 2019, a randomized, double blinded and proof-of-concept clinical trial was started in United States (New York) to assess the effects of extended treatment with CBD (600 and 1,200 mg/day, 4 weeks for each dosing, p.o.) compared to placebo in 40 patients with severe AUD (NCT03252756). In the same year, another randomized, doubleblind and placebo-controlled clinical trial began also in United States (New York) to determine whether CBD (600 mg, 6 weeks, p.o.) is effective in treating AUD in individuals (48 participants) with moderate or severe AUD and comorbid posttraumatic stress disorder (PTSD) (NCT03248167). Finally, another randomized, double-blind, and placebo-controlled clinical trial to explore the effectiveness and tolerability of CBD (1,200 mg/day 1, $800 \mathrm{mg}$ /days $2-4$, p.o.) in the treatment of alcohol withdrawal symptoms in an inpatient setting (52 participants) in Australia (NCT04205682) is expected to start in 2020 .

Thus, the great and growing interest in $\mathrm{CBD}$ as a new drug for AUD management is more than evident. However, further studies are warranted to shed light on the underlying brain mechanisms involved as well as on pharmacokinetics aspects such as dose, treatment duration, route of administration or pharmaceutical formulation.

\section{CBD and Opioids}

Opioid use disorder (OUD) could be defined as a chronic, relapsing illness, associated with significantly increased rates of morbidity and mortality. In the United States, 5.1 million people (1.9 percent of persons age 12 or older) were estimated in 2015 to 
TABLE 3 | Main findings from clinical and animal studies aimed to evaluate the therapeutic potential of CBD for the treatment of opioid use disorder.

\begin{tabular}{|c|c|c|c|c|c|}
\hline \multicolumn{6}{|c|}{ CBD and opioids } \\
\hline Treatment & $\begin{array}{l}\text { Doses, route } \\
\text { of administration, } \\
\text { and treatment } \\
\text { duration }\end{array}$ & $\begin{array}{l}\text { Study design/ } \\
\text { model }\end{array}$ & $\begin{array}{l}\text { Subjects, samples, } \\
\text { and gender }\end{array}$ & Main outcomes & References \\
\hline \multicolumn{6}{|l|}{ Clinical studies } \\
\hline Epidiolex (CBD) & $\begin{array}{l}400 \text { or } 800 \text { mg/day, p.o., } \\
3 \text { days }\end{array}$ & Double-blind RCT & $\begin{array}{l}\text { Patients with heroin use } \\
\text { disorder } N=42 \text { ( } 35 \mathrm{M} \text { and } 7 \mathrm{~F})\end{array}$ & $\begin{array}{l}\downarrow \text { craving and anxiety after acute, short } \\
\text { term and long-term evaluation } \\
\downarrow \text { heart rate after acute and short-term } \\
\text { evaluation } \\
\downarrow \text { cortisol levels }\end{array}$ & Hurd et al. (2019) \\
\hline $\begin{array}{l}\text { APH-1501 } \\
(>98.5 \% \text { CBD, } \\
<0.3 \mathrm{THC})\end{array}$ & $\begin{array}{l}\text { 400, } 600,800 \text { mg/day, } \\
\text { capsules, p.o., } 28 \text { days }\end{array}$ & Triple-blind RCT & $\begin{array}{l}\text { Opioid-dependent patients } \\
N=32(\mathrm{M} / \mathrm{F})\end{array}$ & $\begin{array}{l}\text { - Incidence of treatment adverse effects } \\
\text { - Pharmacokinetics of APH-1501 (no } \\
\text { results posted yet) }\end{array}$ & $\begin{array}{l}\text { ClinicalTrials.gov ID: } \\
\text { NCT03813095 }\end{array}$ \\
\hline Epidiolex (CBD) & $\begin{array}{l}800 \text { mg/day, oral } \\
\text { solution, p.o., } 2 \text { days }\end{array}$ & Open-label & $\begin{array}{l}\text { Methadone-maintained } \\
\text { participants undergoing } \\
\text { spontaneous withdrawal } N= \\
50(\mathrm{M} / \mathrm{F})\end{array}$ & $\begin{array}{l}\text { - Safety as assessed by number of } \\
\text { adverse events } \\
\text { - Number of participants whose AST/ } \\
\text { ALT levels }>3 x \text { upper limit of normal } \\
\text { - Feasibility of spontaneous withdrawal } \\
\text { model as assessed by change in } \\
\text { withdrawal scores (no results posted yet) }\end{array}$ & $\begin{array}{l}\text { ClinicalTrials.gov ID: } \\
\text { NCT04238754 }\end{array}$ \\
\hline \multicolumn{6}{|l|}{ Animal studies } \\
\hline $\mathrm{CBD} \pm \mathrm{THC}$ & $\begin{array}{l}10 \mathrm{mg} / \mathrm{kg} \mathrm{CBD} \pm 2 \mathrm{mg} / \mathrm{kg} \\
\mathrm{THC} \text {, i.p., acute treatment }\end{array}$ & $\begin{array}{l}\text { Naloxone-induced } \\
\text { morphine } \\
\text { abstinence }\end{array}$ & $\begin{array}{l}\text { Sprague-dawley rats } N= \\
33(\mathrm{M})\end{array}$ & $\begin{array}{l}\downarrow \text { morphine withdrawal signs (CBD + } \\
\text { THC combination) }\end{array}$ & Hine et al. (1975) \\
\hline CBD & $\begin{array}{l}5,10,20 \mathrm{mg} / \mathrm{kg} \text {, } \\
\text { i.p., acute treatment }\end{array}$ & $\begin{array}{l}\text { Naloxone-induced } \\
\text { morphine } \\
\text { withdrawal }\end{array}$ & Swiss-webster mice (M) & $\begin{array}{l}\uparrow \text { dose of naloxone needed to induce } \\
\text { morphine withdrawal jumping in } 50 \% \text { of } \\
\text { the animals (ED50) } \\
\downarrow \text { jumping, defecations, and rearing } \\
\text { behaviors }\end{array}$ & Bhargava. (1976) \\
\hline CBD & $\begin{array}{l}5,20,80 \mathrm{mg} / \mathrm{kg} \\
\text { i.p., acute treatment }\end{array}$ & $\begin{array}{l}\text { Quasi-morphine } \\
\text { withdrawal } \\
\text { syndrome }\end{array}$ & Sprague-dawley rats (M) & $=$ Withdrawal score & $\begin{array}{l}\text { Chesher \& Jackson. } \\
\text { (1985) }\end{array}$ \\
\hline CBD & $\begin{array}{l}5 \mathrm{mg} / \mathrm{kg} \text {, i.p., acute } \\
\text { treatment }\end{array}$ & $\begin{array}{l}\text { Morphine-induced } \\
\text { ICSS }\end{array}$ & Sprague-dawley rats (M) & $\begin{array}{l}\otimes \text { reward-facilitating morphine effects } \rightarrow \\
\text { abolished by WAY }\end{array}$ & Katsidoni et al. (2013) \\
\hline CBD & $\begin{array}{l}5,10 \mathrm{mg} / \mathrm{kg}, \text { s.c., acute } \\
\text { treatment }\end{array}$ & $\begin{array}{l}\text { Morphine-induced } \\
\text { CPP, naltrexone- } \\
\text { induced CPA }\end{array}$ & Wistar rats $\mathrm{N}=295(\mathrm{M})$ & $\begin{array}{l}\downarrow \mathrm{CPP} \\
\otimes \text { morphine priming- or stress-induced } \\
\text { CPP reinstatement } \\
\otimes \text { naltrexone-induced CPA }\end{array}$ & $\begin{array}{l}\text { de Carvalho \& } \\
\text { Takahashi. (2017) }\end{array}$ \\
\hline CBD & $\begin{array}{l}2.5,5,10,20 \mathrm{mg} / \mathrm{kg} \text {, } \\
\text { i.p., acute treatment }\end{array}$ & $\begin{array}{l}\text { Morphine- } \\
\text { induced CPP }\end{array}$ & C57BL/6 mice $N=100(M)$ & $\downarrow \mathrm{CPP}$ & Markos et al. (2018) \\
\hline CBD & $\begin{array}{l}5,10,20 \mathrm{mg} / \mathrm{kg} \text {, } \\
\text { i.p., acute treatment }\end{array}$ & Heroin-induced ISA & Long-evans rats (M) & $\begin{array}{l}=\text { Heroin ISA } \\
=\text { priming-induced heroin seeking } \\
\downarrow \text { cue-induced heroin seeking }\end{array}$ & Ren et al. (2009) \\
\hline
\end{tabular}

CBD, cannabidiol; THC, tetrahydrocannabinol; RCT, randomized clinical trial; CPP, conditioned place preference; CPA, conditioned place aversion; ISA, intravenous self-administration; WAY, WAY-100635 (5HT1a selective antagonist); M, male; F, female; p.o., per os (oral administration); i.p., intraperitoneal injection; $\uparrow$, increase; $\downarrow$, decrease; = , no effect; $\otimes$, blockade.

have used heroin at some point in their lives (Hser et al., 2015; Substance Abuse and Mental Health Services Administration, 2016). Patients may develop OUD by acquiring illegal opioid drugs (e.g., heroin), by obtaining them legally but use them for not legitimate medical purposes (morphine, fentanyl, oxycodone, etc.), or at doses in excess to the needed for the medical condition (APA, 2013). One of the major concerns associated with OUD is the occurrence of opioid overdose with high rates of mortality, especially in United States were recent data show a significant increase (Rudd et al., 2016). Currently, the FDA and the EMA authorize the marketing of three classes of medications: 1) the short-acting opioid antagonist naloxone employed to reverse the life-threatening effects of opioid overdose, 2) oral opioid agonists methadone and buprenorphine, highly effective and widely employed in opioid maintenance programs to achieve abstinence and avoid relapse, and 3) the alpha 2-adrenergic agonist lofexidine, recently approved by the FDA representing the first non-opioid medication indicated for mitigation of symptoms associated with acute opioid withdrawal and for facilitation of the completion of opioid discontinuation treatment (Gorodetzky et al., 2017; Guo et al., 2018). Nowadays, buprenorphine (BPN) has been proposed as one of the first-line treatments for OUD management due to its low abuse potential, reduced risk of overdose and flexible dosing in comparison with methadone (Li et al., 2014). However, recent evidence points out poor patient retention in BPN maintenance (Bell, 2014; Hser et al., 2014; Mattick et al., 2014; Burns et al., 2015). This fact together with the limited efficacy of current 
options for the treatment of OUD motivates the development of new mechanistically based pharmacological strategies that go beyond treating symptoms associated with opioid withdrawal syndrome to relapse. CBD may serve as a new therapeutic strategy for the treatment of OUD, not simply for withdrawal symptomatic relief partly due to its anxiolytic properties, but also to reduce craving and avoiding relapse (Table 3).

The first evidence on the possible therapeutic utility of CBD in the regulation of pharmacologically induced morphine withdrawal was reported in 1975. The effects of CBD $(10 \mathrm{mg} / \mathrm{kg}$, i.p.), alone or combined with THC $(2 \mathrm{mg} / \mathrm{kg}$, i.p.), on naloxone-induced morphine abstinence were evaluated in male Sprague-Dawley rats. THC and especially CBD plus THC combination significantly attenuated morphine withdrawal signs whereas no effects were found with $\mathrm{CBD}$ alone (Hine et al., 1975). Shortly another study evaluated the effects of some cannabinoid compounds on naloxoneprecipitated abstinence signs in Swiss-Webster male mice. Interestingly, $\mathrm{CBD} \quad(5$ and $10 \mathrm{mg} / \mathrm{kg}$, i.p.) significantly increased the dose of naloxone needed to induce morphine withdrawal jumping in $50 \%$ of the animals (ED50), although it was not the most effective cannabinoid (Bhargava, 1976). To further elucidate the therapeutic potential of cannabinoid compounds to modulate morphine withdrawal, Chesher and Jackson analyzed whether cannabinol, CBD or THC attenuate the signs associated with the quasi-morphine withdrawal syndrome in male Sprague-Dawley rats. THC and cannabinol significantly reduced the withdrawal score whereas CBD was without effect at the dosage levels used (5, 20 and $80 \mathrm{mg} / \mathrm{kg}$, i.p.) (Chesher and Jackson, 1985).

More recently, it was reported that CBD might interfere with brain reward mechanisms responsible for the expression of the acute reinforcing properties of opioids such as morphine. Indeed, authors showed that CBD inhibited the reward-facilitating effect of morphine employing the intracranial self-stimulation (ICSS) paradigm. Interestingly, pre-treatment with an intra-dorsal raphe injection of the selective 5HT1a receptor antagonist WAY100635 reversed the effects of CBD, suggesting the involvement of these receptors in the CBD-mediated inhibition of morphine-induced reward (Katsidoni et al., 2013). Also, the efficacy of CBD to regulate morphine-induced CPP was investigated by two independent studies. First, in male Wistar rats the administration of CBD $(10 \mathrm{mg} / \mathrm{kg}$, i.p.) blocked place conditioning behavior and reinstatement induced by a priming dose of morphine or stress exposure (de Carvalho and Takahashi, 2017). Second, in male C57BL/6J mice the same dose of $\mathrm{CBD}$ also significantly attenuated morphineinduced CPP (Markos et al., 2018).

Heroin is a morphine derivative with a higher addictive power and is usually consumed first by patients starting the use of opioids (Cicero et al., 2017). To evaluate if the administration of CBD could modify the reinforcing and motivational properties of heroin, Ren et al. employed an animal model of heroin intravenous SA. They assessed the actions of CBD on heroin $\mathrm{SA}$ and relapse induced by a heroin prime injection or the exposure to conditioned contextual cues. The administration of CBD (5 or $20 \mathrm{mg} / \mathrm{kg}$, i.p.) was without effect on heroin consumption and did not prevent relapse by a priming dose of heroin. However, it significantly attenuated the reinstatement of cue-induced heroin seeking. Interestingly, CB1R and glutamatergic mGluR5 and GluR1 gene and/or protein alterations were normalized with CBD treatment (Ren et al., 2009). A few years later, a double-blind randomized placebocontrolled clinical trial evaluated the utility of CBD (400 or $800 \mathrm{mg}$ ) to reduce cue-induced craving and anxiety in drugabstinent patients with heroin use disorder. The results showed that the administration of CBD reduces both craving and anxiety induced by the presentation of heroin-related salient drug cues. Furthermore, CBD also attenuated drug cue-induced physiological measures of heart rate and salivary cortisol levels in heroin abstinent patients. Remarkably, these effects were maintained one week after the end of the CBD short-term administration (Hurd et al., 2019). Finally, it is relevant to mention that an exploratory dose ranging study was recently posted in ClinicalTrials.gov to assess the safety, efficacy, and tolerability of APH-1501 ( $>98.5 \% \mathrm{CBD},<0.3 \mathrm{THC}$ ) for the treatment of opioid dependence. This clinical trial will target opioid-dependent patients completing detoxification in a treatment facility. These will be randomized into 4 treatment groups receiving APH-1501 $\left(400,600\right.$ or $\left.800 \mathrm{mg} / \mathrm{m}^{2}\right)$ or placebo over a 30 day period (NCT03813095). Also, another pilot study sponsored by the Johns Hopkins University has been proposed to examine the safety of CBD (Epidiolex) in a human laboratory model of clinically relevant opioid withdrawal. In a residential, randomized and within-subject comparison design, authors will evaluate the effects of placebo and CBD $(800 \mathrm{mg})$ in methadonemaintained patients undergoing spontaneous withdrawal (NCT04238754).

In summary, to date few studies have attempted to demonstrate the efficacy of CBD in opioid addiction. The achievement of promising results lately has motivated further research to evaluate the potential utility of $\mathrm{CBD}$ in the management of OUD.

\section{CBD and Psychostimulants}

Stimulant use disorder is defined by the DSM- 5 as the continued use of amphetamine-type substances, cocaine, or other stimulants leading to clinically significant impairment or distress, from mild to severe (APA, 2013). The global prevalence of stimulant use has increased over the past decade with a worrying rise in the use of amphetamine-type stimulants and cocaine (United Nations Office on Drugs and Crime, 2019). Amphetamine-type stimulants include substances with a similar chemical structure, such as amphetamine and methamphetamine, and other structurally different but with similar effects, such as methylphenidate. Amphetamine-type stimulants as well as cocaine are highly addictive substances. One of the main concerns is the lack of specific pharmacological tools for the treatment of amphetamine-type or cocaine use disorder. Although psychostimulants have shown some favorable results, high quality clinical trials and meta-analyses are needed to determine their clinical utility (Ronsley et al., 2020). Thus, it is essential to search for new therapeutic approaches. In the last years, many authors evaluated the therapeutic utility of $\mathrm{CBD}$ to 
TABLE 4 | Main findings from clinical and animal studies aimed to evaluate the therapeutic potential of CBD for the treatment of stimulant use disorder.

\begin{tabular}{|c|c|c|c|c|c|}
\hline \multicolumn{6}{|c|}{ CBD and psychostimulants } \\
\hline Treatment & $\begin{array}{l}\text { Doses, route } \\
\text { of administration, } \\
\text { and treatment } \\
\text { duration }\end{array}$ & $\begin{array}{l}\text { Study design/ } \\
\text { model }\end{array}$ & $\begin{array}{l}\text { Subjects, } \\
\text { samples, } \\
\text { and gender }\end{array}$ & Main outcomes & References \\
\hline \multicolumn{6}{|c|}{ Amphetamine/methamphetamine } \\
\hline CBD & $\begin{array}{l}5 \mathrm{mg} / \mathrm{kg} \text {, i.p., } 4 \text { days (conditioning } \\
\text { pase of CPP) or } 1 \text { day (extinction } \\
\text { trial) }\end{array}$ & AMPH-induced CPP & $\begin{array}{l}\text { Sprague-dawley } \\
\text { rats }(\mathrm{M})\end{array}$ & $\begin{array}{l}=\text { Conditioning score } \\
\uparrow \text { CPP extinction }\end{array}$ & Parker et al. (2004) \\
\hline CBD & $10 \mu \mathrm{g} / 5 \mu \mathrm{l}, \mathrm{ICV}$, acute treatment & METH-induced CPP & Wistar rats $(\mathrm{M})$ & $\begin{array}{l}\downarrow \text { METH-induced CPP reinstatement (high } \\
\text { priming dose) } \\
\downarrow \text { METH-induced CPP reinstatement (low } \\
\text { priming dose in REM sleep deprived rats) }\end{array}$ & $\begin{array}{l}\text { Karimi-Haghighi \& } \\
\text { Haghparast. (2018) }\end{array}$ \\
\hline $\mathrm{CBD}$ & $\begin{array}{l}\text { 10, } 20,40,80 \mathrm{mg} / \mathrm{kg} \text {, } \\
\text { i.p., repeated treatment (METH- } \\
\text { paired conditioning sessions) }\end{array}$ & METH-induced CPP & $\begin{array}{l}\text { Sprague-dawley } \\
\text { rats (M) }\end{array}$ & $\begin{array}{l}\downarrow \text { METH-induced CPP (dose- } \\
\text { dependently) }\end{array}$ & Yang et al. (2020) \\
\hline CBD & $\begin{array}{l}0,20,40 \text { and } 80 \mathrm{mg} / \mathrm{kg} \text {, i.p., acute } \\
\text { treatment }\end{array}$ & METH-induced ISA & $\begin{array}{l}\text { Male sprague- } \\
\text { dawley rats } N= \\
32(\mathrm{M})\end{array}$ & $\begin{array}{l}\downarrow \text { motivation to self-administer METH } \\
\downarrow \text { METH-primed relapse after extinction }\end{array}$ & Hay et al. (2018) \\
\hline CBD & $\begin{array}{l}32 \text { and } 160 \mathrm{nmol}, \mathrm{ICV}, 10 \text { days } \\
\text { (abstinence) }\end{array}$ & $\begin{array}{l}\text { Chronic exposure to } \\
\text { METH }\end{array}$ & $\begin{array}{l}\text { Wistar rats } N= \\
62(\mathrm{M})\end{array}$ & $\uparrow$ long-term memory in the NOR test & Razavi et al. (2020) \\
\hline \multicolumn{6}{|l|}{ Cocaine } \\
\hline CBD & $\begin{array}{l}5 \mathrm{mg} / \mathrm{kg} \text {, i.p., } 4 \text { days (conditioning } \\
\text { phase of CPP) or } 1 \text { day (extinction } \\
\text { trial) }\end{array}$ & $\begin{array}{l}\text { Cocaine- } \\
\text { induced CPP }\end{array}$ & $\begin{array}{l}\text { Sprague-dawley } \\
\text { rats (M) }\end{array}$ & $\begin{array}{l}=\text { Conditioning score } \\
\uparrow \text { CPP extinction }\end{array}$ & Parker et al. (2004) \\
\hline CBD & 10 mg/kg, i.p., acute treatment & $\begin{array}{l}\text { Cocaine- } \\
\text { induced CPP }\end{array}$ & $\begin{array}{l}\text { Wistar rats } N= \\
295(\mathrm{M})\end{array}$ & $\begin{array}{l}\downarrow \text { reconsolidation of cocaine- } \\
\text { induced CPP }\end{array}$ & $\begin{array}{l}\text { de Carvalho \& Takahashi. } \\
\text { (2017) }\end{array}$ \\
\hline CBD & $\begin{array}{l}10 \mathrm{mg} / \mathrm{kg} \text {, i.p., acute and repeated } \\
\text { administration }\end{array}$ & $\begin{array}{l}\text { Cocaine- } \\
\text { induced CPP }\end{array}$ & C57BL/6J mice (M) & $\begin{array}{l}\downarrow \text { preference for the cocaine context } \\
\downarrow \text { consolidation of cocaine memory } \\
=\text { cocaine-induced CPP } \\
=\text { Rate of extinction of cocaine memory } \\
=\text { cocaine-primed reinstatement }\end{array}$ & Chesworth \& Karl. (2020) \\
\hline CBD & $\begin{array}{l}30,60 \mathrm{mg} / \mathrm{kg} \text {, i.p., acute } \\
\text { treatment }\end{array}$ & $\begin{array}{l}\text { Cocaine- } \\
\text { induced CPP }\end{array}$ & $\begin{array}{l}\text { CD1 mice } N= \\
120(\mathrm{M})\end{array}$ & $\begin{array}{l}\downarrow \text { cocaine-primed reinstatement } \\
\downarrow \text { social defeat-induced reinstatement }\end{array}$ & Calpe-Lopez et al. (2020) \\
\hline CBD & 10, 20 mg/kg, i.p., 10 days & $\begin{array}{l}\text { Cocaine- } \\
\text { induced ISA }\end{array}$ & CD1 mice $(\mathrm{M})$ & $\begin{array}{l}\downarrow \text { cocaine self-administration and } \\
\text { motivation } \rightarrow \text { abolished by hippocampal } \\
\text { neurogenesis blockade (temozolomide) } \\
=\text { cocaine-induced reinstatement }\end{array}$ & $\begin{array}{l}\text { Calpe-Lopez et al. (2020) } \\
\text { and Luján et al. (2019) }\end{array}$ \\
\hline CBD & $\begin{array}{l}\text { 3-20 mg/kg, i.p., repeated } \\
\text { administration }\end{array}$ & $\begin{array}{l}\text { Cocaine- } \\
\text { induced ISA } \\
\text { Cocaine- } \\
\text { induced BSR }\end{array}$ & $\begin{array}{l}\text { Long-evans rats } \\
N=75(\mathrm{M})\end{array}$ & $\begin{array}{l}\downarrow \text { cocaine self-administration with low but } \\
\text { not high cocaine doses } \\
\downarrow \text { cocaine-enhanced BSR }\end{array}$ & Galaj et al. (2020) \\
\hline CBD & 15 mg/kg/day, t.d. 7 days & $\begin{array}{l}\text { Cocaine- } \\
\text { induced ESA }\end{array}$ & $\begin{array}{l}\text { Wistar rats } N= \\
52(\mathrm{M})\end{array}$ & $\begin{array}{l}\downarrow \text { context-induced and stress-induced } \\
\text { reinstatement }\end{array}$ & $\begin{array}{l}\text { Gonzalez-Cuevas et al. } \\
\text { (2018) }\end{array}$ \\
\hline $\begin{array}{l}\mathrm{CBD}+ \\
\text { caffeine }\end{array}$ & $\begin{array}{l}20 \text { mg/kg, i.p. Repeated } \\
\text { administration }\end{array}$ & $\begin{array}{l}\text { Cocaine-induced } \\
\text { locomotor } \\
\text { sensitization }\end{array}$ & Wistar rats $(\mathrm{M})$ & $\downarrow$ cocaine-induced hyperlocomotion & Prieto et al. (2020) \\
\hline CBD & $\begin{array}{l}\text { 10, } 20,40 \text { mg/kg, i.p.Cocaine- } \\
\text { induced BSR Acute treatment }\end{array}$ & $\begin{array}{l}\text { Spontaneous } \\
\text { cocaine withdrawal }\end{array}$ & $\begin{array}{l}\text { CD1 mice } N= \\
100(\mathrm{M})\end{array}$ & $\begin{array}{l}\downarrow \text { anxiety level } \\
\downarrow \text { hyperactivity } \\
\downarrow \text { withdrawal somatic signs }\end{array}$ & Gasparyan et al. (2020) \\
\hline CBD & $5 \mathrm{mg} / \mathrm{kg}$, i.p. Acute treatment & $\begin{array}{l}\text { Cocaine-induced } \\
\text { ICSS }\end{array}$ & $\begin{array}{l}\text { Sprague-dawley } \\
\text { rats (M) }\end{array}$ & = reward-facilitating effect of cocaine & Katsidoni et al. (2013) \\
\hline CBD & $\begin{array}{l}5 \text { and } 10 \mathrm{mg} / \mathrm{kg} \text {, i.p. Chronic and } \\
\text { acute treatment }\end{array}$ & $\begin{array}{l}\text { Cocaine- } \\
\text { induced ISA }\end{array}$ & $\begin{array}{l}\text { Long-evans rats } \\
N=40(\mathrm{M})\end{array}$ & $\begin{array}{l}=\text { Cocaine self-administration } \\
=\text { Cocaine seeking after withdrawal }\end{array}$ & Mahmud et al. (2017) \\
\hline CBD & 400 or 800 mg/day & Double-blind RCT & $\begin{array}{l}\text { Cocaine- } \\
\text { dependent } \\
\text { individuals } N=79 \\
\text { (M/F) }\end{array}$ & $\begin{array}{l}\text { Drug-cue induced craving } \\
\text { Number of days to relapse (no results } \\
\text { posted yet) }\end{array}$ & $\begin{array}{l}\text { ClinicalTrials.gov ID: } \\
\text { NCT02559167 }\end{array}$ \\
\hline
\end{tabular}

CBD, cannabidiol; $A M P H$, amphetamine; METH, methamphetamine; CPP, conditioned place preference; ICSS, intracranial self-stimulation; ISA, intravenous self-administration; BSR, brain stimulation reward; NOR, novel object recognition; REM, rapid eye movement; $R C T$, randomized clinical trial; $M$, male; $F$, female; p.o., per os (oral administration); i.p., intraperitoneal injection; ICV, intracerebroventricular; $\uparrow$, increase; $\downarrow$, decrease; = , no effect. 
treat the different phases of dependence to psychostimulants. As reviewed below, published reports focused mainly on evaluating the effects of $\mathrm{CBD}$ on the reinforcing and motivational actions of amphetamine, methamphetamine, and cocaine in different animal models (Table 4).

\section{Amphetamine-type Substance Use Disorder}

The potential of $\mathrm{CBD}$ to modulate amphetamine-induced rewarding properties was first reported in 2004. In this study, the administration of a low dose of CBD (5 mg/kg, i.p.) potentiated the extinction of amphetamine-induced CPP without affecting the learning process of place conditioning (Parker et al., 2004). Years later, another group showed that intracerebroventricular (ICV) injection of CBD $(10 \mu \mathrm{g} / 5 \mu \mathrm{l})$ suppressed the methamphetamineinduced reinstatement in the CPP paradigm, even under stressed conditions (Karimi-Haghighi and Haghparast, 2018). Interestingly, these authors suggested later that the effect of CBD was associated with the normalization of methamphetamine-induced increase of gene expression of cytokines (interleukin-1 $\beta$, interleukin-6, interleukin-10, and tumor necrosis factor $\alpha$ (TNF- $\alpha)$ ) in the prefrontal cortex (PFC) and HIPP. However, in REM sleepdeprived rats CBD produced opposite effects (Karimi-Haghighi et al., 2020). Recently, CBD-mediated regulation of methamphetamine-induced CPP was further confirmed. Treatment with CBD $(10,20,40$ and $80 \mathrm{mg} / \mathrm{kg}$, i.p. $) 1 \mathrm{~h}$ prior to the administration of methamphetamine during conditioning sessions significantly and dose dependently attenuated CPP. Importantly, these effects were related with the regulation of the SigmaR1/AKT/GSK-3 $\beta / C R E B$ signaling pathway that was upregulated in the VTA, NAcc, HIPP, and PFC of methamphetamine-treated male Sprague-Dawley rats (Yang et al., 2020). Apart from the effects of CBD on CPP induced by amphetamine and methamphetamine, Hay et al. explored whether CBD modulates the motivation to obtain methamphetamine as well as the relapse into methamphetamine consumption using an intravenous SA paradigm. After a training phase, the administration of CBD $(80 \mathrm{mg} / \mathrm{kg}$, i.p.) significantly reduced active lever pressing and consequently the number of methamphetamine infusions, as well as methamphetamineprimed relapse to active lever pressing (Hay et al., 2018).

Chronic exposure to amphetamine-type derivatives could lead to neurodegeneration and neuro-inflammation phenomena with associated cognitive impairments. Therefore, in addition to the interest of modulating rewarding and motivational properties, it is also important to provide a neuroprotective effect to attenuate these alterations. In this sense, a recent report revealed that the ICV administration of CBD during the abstinence period after chronic exposure to methamphetamine (10 days) significantly reverses long-term memory in the novel object recognition test (Razavi et al., 2020). However, more studies are needed to further explore the therapeutic potential of CBD and to elucidate the neurobiological mechanisms involved.

\section{Cocaine Use Disorder}

One of the first reports suggesting the therapeutic potential of CBD for the modulation of cocaine rewarding properties employed the CPP paradigm. In Sprague-Dawley rats, CBD
( $5 \mathrm{mg} / \mathrm{kg}$, i.p.) did not change the conditioning score but enhanced CPP extinction (Parker et al., 2004). Also, CBD $(10 \mathrm{mg} / \mathrm{kg}$, i.p.) disrupted the reconsolidation of place preference in rats and this effect was present for 2 weeks (de Carvalho and Takahashi, 2017). Very recently, Chesworth and Karl exhaustively explored CBD actions $(10 \mathrm{mg} / \mathrm{kg}$, i.p.) on the acquisition, consolidation, reconsolidation, extinction, and drugprimed reinstatement of cocaine $(15 \mathrm{mg} / \mathrm{kg})$ in the CPP paradigm. CBD significantly reduced the preference for the cocaine-context and the consolidation of cocaine memory. CBD had no effects on cocaine-induced CPP, the rate of extinction of cocaine memory, or the drug-primed reinstatement (Chesworth and Karl, 2020). However, a recent report of our group demonstrated that CBD $(30$ and $60 \mathrm{mg} / \mathrm{kg}$, i.p.) significantly reduced cocaine priming- and social defeatinduced reinstatement of CPP (Calpe-Lopez et al., 2020). Likewise, Lujan et al. demonstrated that CBD (10 and $20 \mathrm{mg} / \mathrm{kg}$, i.p.) significantly attenuated cocaine-induced CPP. Furthermore, they employed an intravenous SA paradigm and showed that $\mathrm{CBD}(20 \mathrm{mg} / \mathrm{kg}$, i.p.) reduced the motivation to selfadminister cocaine in a fixed ratio 1 schedule, as well as the breaking point during the progressive ratio stage. Interestingly, CBD effects on cocaine-induced reward and motivation could be related with an increase of CB1R and brain-derived neurotrophic factor (BDNF) expression, MAPK/CREB pathway phosphorylation and neural progenitor proliferation in the HIPP whereas a reduction of GluA1/2 AMPA subunit receptor ratio was found in the striatum of male $\mathrm{CD} 1$ mice that underwent cocaine SA (Luján et al., 2018). Also, it is relevant to point out that the effects of CBD on hippocampal neurogenesis plays a pivotal role in the reduction of cocaine SA (Luján et al., 2019). Recently, attenuating effects of $\mathrm{CBD}$ on the motivational properties of cocaine were also revealed by Galaj et al.. In this study CBD inhibited cocaine SA maintained by low, but not high, doses of cocaine, and dose-dependently lowered cocaine-enhanced brainstimulation reward. Importantly, these effects were abolished by the blockade of CB2R, 5HT1a and TRPV1 suggesting their functional implication. Furthermore, in vivo microdialysis revealed a CBD-mediated reduction of cocaine-induced increases in extracellular dopamine in the NAcc (Galaj et al., 2020).

In addition to these previous findings, it was also explored whether CBD could be effective to prevent relapse. GonzalezCuevas et al. revealed that the transdermal administration of CBD attenuated context-induced and stress-induced drug-seeking in an intravenous cocaine SA paradigm. Interestingly, CBD-mediated anti-relapsing effects were maintained up to 5 months after the end of the treatment although plasma and brain $\mathrm{CBD}$ levels were undetectable at this time (Gonzalez-Cuevas et al., 2018). Furthermore, the effects of $\mathrm{CBD}$ on cocaine plus caffeineinduced locomotor sensitization were investigated. Repeated treatment with CBD $(20 \mathrm{mg} / \mathrm{kg}$, i.p.) blunted the motor behavioral response induced by a challenge dose of cocaine plus caffeine (Prieto et al., 2020).

Another crucial aspect in the cocaine use disorder is the successful management of cocaine-induced withdrawal syndrome to maintain the abstinence and to prevent relapse. 
Recently, our group evaluated the role of CBD to regulate behavioral and neurobiological alterations induced by cocaine in a new animal model of spontaneous withdrawal. The results of this study revealed that $\mathrm{CBD}(10,20$, and $40 \mathrm{mg} / \mathrm{kg}$, i.p.) normalized motor and somatic signs disturbances and completely regulated anxiety-like behaviors induced by spontaneous cocaine withdrawal (progressive increasing doses of cocaine for 12 days, $15-60 \mathrm{mg} / \mathrm{kg} /$ day, i.p.). Furthermore, the administration of CBD blocked the increase of dopamine transporter (DAT) and TH gene expressions in the VTA of mice exposed to the cocaine withdrawal (Gasparyan et al., 2020).

On the contrary to the positive findings supporting the therapeutic potential of $\mathrm{CBD}$ in the regulation of the reinforcing and motivational actions of cocaine, one study found that $\mathrm{CBD}(5 \mathrm{mg} / \mathrm{kg}$, i.p.) did not modify the rewardfacilitating effect of cocaine in the ICSS paradigm (Katsidoni et al., 2013). Also, another publication showed that CBD (5 and $10 \mathrm{mg} / \mathrm{kg}$, i.p.) did not attenuate the motivation to self-administer cocaine (breaking point) nor the cue-induced cocaine seeking in rats after a withdrawal period (Mahmud et al., 2017). These apparently contradictory results could be related, at least in part, with differences in the experimental design or in the administered doses of cocaine and CBD. However, the available information suggests that $\mathrm{CBD}$ could be a useful tool for the treatment of cocaine use disorder although additional studies are warranted.

Finally, a double-blind, randomized and placebo-controlled clinical trial was carried out in 79 patients with cocaine use disorder. The main goal was to evaluate the effects of CBD (400 or $800 \mathrm{mg} /$ day) on cocaine-cue induced craving and the number of days to relapse. Although the results have not yet been published, the performance of this study points out the interest of the therapeutic potential of CBD for cocaine use disorder (NCT02559167).

\section{CBD and Nicotine}

Tobacco use is the cause of over 8 million deaths per year globally, resulting one of the biggest public health threats worldwide (World Health Organization (WHO), 2020). Nicotine is the main addictive substance responsible for cigarette smoking and withdrawal symptoms occurring upon smoking cessation. Nowadays, nicotine replacement therapy together with varenicline, a nicotinic receptor partial agonist, is the most effective smoking cessation drug. However, a significant proportion or smokers still fail to maintain long-term abstinence. Here we reviewed the scarce but recent results pointing out $\mathrm{CBD}$ as a candidate to be considered for modulating nicotine-induced reinforcing and withdrawal symptoms.

The first pilot clinical study evaluated the effects of CBD in smokers trying to achieve cessation. Inhaled CBD $(400 \mu \mathrm{g} /$ inhalation) was effective to reduce the number of cigarettes smoked after one week of treatment. Nevertheless, CBD treatment did not attenuate nicotine craving and showed only a slight, non-significant reduction in anxiety after the 7 days treatment (Morgan et al., 2013). A few years later, the administration of a single dose of CBD ( $800 \mathrm{mg})$ in nontreatment seeking, dependent, cigarette smokers after overnight abstinence did not improve verbal or spatial working memory, or impulsivity (Hindocha et al., 2018). However, the same group demonstrated that CBD (single $800 \mathrm{mg}$ dose) reduced attentional bias after a period of tobacco abstinence without improving craving or withdrawal (Hindocha et al., 2018). Recently, a preclinical study was conducted to analyze the effects of CBD (10 and $30 \mathrm{mg} / \mathrm{kg})$ in mice exposed to an animal model of pharmacologically precipitated nicotine withdrawal. Interestingly, CBD abolishes memory impairment and microglial reactivity induced by nicotine withdrawal (Saravia et al., 2019).

In summary, although the information on this issue is very limited, it appears that CBD may result an interesting therapeutic alternative for tobacco dishabituation (Table 5). However, further studies should be conducted to improve our knowledge of its usefulness and to increase our understanding of the possible mechanisms involved.

\section{NEUROBIOLOGICAL MECHANISMS INVOLVED IN CBD-MEDIATED REGULATION OF ADDICTION}

This section is aimed to analyze in an integrated way the mechanisms that could be underlying the "anti-addictive" actions of CBD. For that purpose, the most representative functional brain systems have been selected to dissect which targets and regulatory mechanisms may be modulated by CBD.

\section{CBD and Dopaminergic System}

The scientific community has long accepted the dopaminergic theory of addiction. The hedonic effects of different drugs of abuse are mediated mainly, at least initially, by the release of DA in the mesocorticolimbic system that comprises dopaminergic neurons projecting from the VTA to the NAcc. Released DA in the NAcc acts on high affinity D2 receptors and determines drug rewarding effects (Trifilieff et al., 2013). Also, DA stimulates the low-affinity D1 receptors associated with the consolidation of recent memory engrams (Wise, 2004). However, increased DA levels are not always present after the exposure to a drug of abuse since addiction encompasses a complex functional regulation including the interaction between different neurotransmission systems (Nutt et al., 2015). Despite this, the dopaminergic system plays a central role in addictive disorders.

Little is known about the effects of CBD on the mesolimbic system. One of the first reports revealed that systemically administered CBD had neither excitatory nor inhibitory effects on spontaneously recorded VTA dopaminergic neuronal activity levels (French et al., 1997). In accordance with this finding, systemic injections of CBD alone (10 and $20 \mathrm{mg} / \mathrm{kg}$, i.p.) failed to significantly alter extracellular DA level in the NAcc (Galaj et al., 2020). However, intra-hypothalamic administration of CBD was reported to increase the release of dopamine extracellular levels collected from the NAcc (MurilloRodríguez et al., 2011). Due to the antipsychotic actions of $\mathrm{CBD}$, along with the absence of extrapyramidal effects, numerous studies have been conducted to investigate the 
TABLE 5 | Main findings from clinical and animal studies aimed to evaluate the therapeutic potential of CBD for the treatment of tobacco use disorder.

\begin{tabular}{|c|c|c|c|c|c|}
\hline \multicolumn{6}{|c|}{ CBD and nicotine } \\
\hline Treatment & $\begin{array}{l}\text { Doses, route } \\
\text { of administration, } \\
\text { and treatment } \\
\text { duration }\end{array}$ & Study design/model & $\begin{array}{l}\text { Subjects, samples, } \\
\text { and gender }\end{array}$ & Main outcomes & References \\
\hline \multicolumn{6}{|c|}{ Clinical studies } \\
\hline CBD & $\begin{array}{l}400 \mu \mathrm{g} / \text { inhalation solution } \\
\text { erosol, inh. } 7 \text { days }\end{array}$ & $\begin{array}{l}\text { Double-blind placebo- } \\
\text { controlled trial }\end{array}$ & Smokers $N=24(12 \mathrm{M}$ and $12 \mathrm{~F})$ & $\downarrow$ number of cigarettes smoked & $\begin{array}{l}\text { Morgan et al. } \\
\text { (2013) }\end{array}$ \\
\hline CBD & 800 mg, p.o. Acute treatment & $\begin{array}{l}\text { Double-blind placebo- } \\
\text { controlled trial }\end{array}$ & $\begin{array}{l}\text { Non-treatment seeking dependent } \\
\text { smokers } N=30 \text { (15 M and } 15 \mathrm{~F})\end{array}$ & $\begin{array}{l}=\text { Verbal or spatial working } \\
\text { memory } \\
=\text { withdrawal-induced impulsivity }\end{array}$ & $\begin{array}{l}\text { Hindocha et al. } \\
\text { (2018) }\end{array}$ \\
\hline CBD & 800 mg, p.o. Acute treatment & $\begin{array}{l}\text { Double-blind placebo- } \\
\text { controlled trial }\end{array}$ & $\begin{array}{l}\text { Non-treatment seeking dependent } \\
\text { smokers } N=30 \text { (16 M and } 14 \mathrm{~F})\end{array}$ & $\begin{array}{l}\downarrow \text { attentional bias } \\
\downarrow \text { pleasantness of cigarette } \\
\text { images } \\
=\text { Tobacco craving } \\
=\text { Withdrawal symptoms }\end{array}$ & $\begin{array}{l}\text { Hindocha et al. } \\
\text { (2018) }\end{array}$ \\
\hline \multicolumn{6}{|c|}{ Animal studies } \\
\hline CBD & $\begin{array}{l}3,10 \text { and } 30 \mathrm{mg} / \mathrm{kg}, \text { s.c. } \\
\text { Repeated treatment }\end{array}$ & $\begin{array}{l}\text { Precipitated nicotine } \\
\text { withdrawal }\end{array}$ & C57BL/6J mice (M) & $\begin{array}{l}\uparrow \text { NOR discrimination index } \\
\text { during nicotine withdrawal }\end{array}$ & $\begin{array}{l}\text { Saravia et al. } \\
\text { (2019) }\end{array}$ \\
\hline
\end{tabular}

CBD, cannabidiol; NOR, novel object recognition; $M$, male; F, female; inh., inhaled; p.o., per os (oral administration); s.c., subcutaneous injection; $\uparrow$, increase; $\downarrow$ : decrease, = ; no effect.

interaction between $\mathrm{CBD}$ and the mesolimbic dopaminergic system employing animal models of schizophrenia. It has been proposed that $\mathrm{CBD}$ could act as a partial agonist of $\mathrm{D} 2$ receptors (Seeman, 2016) and normalize D3 receptor gene expression in several brain regions (PFC, HIPP, and NAcc) (Stark et al., 2020).

Considering the "anti-addictive" properties of CBD, previously mentioned in this review, it is important to determine how CBD modulates drug-induced alterations in the mesolimbic dopaminergic system. One of the first evidence was published by Renard et al., in an animal model of amphetamine-induced locomotor sensitization. They demonstrated that direct administration of CBD into the shell region of the NAcc completely abolished VTA dopaminergic neuronal activity sensitization induced by amphetamine (Renard et al., 2016). Interestingly, in vivo microdialysis studies revealed that systemic administration of CBD (10 and $20 \mathrm{mg} / \mathrm{kg}$, i.p.) dosedependently attenuated cocaine-induced DA release in the NAcc (Galaj et al., 2020). This effect could be explained by the hypothetical modulation of DA synthesis in the VTA. Indeed, our group has extensively explored the effects of CBD on druginduced gene expression changes of $\mathrm{TH}$, the rate limiting enzyme for dopamine synthesis in the VTA. In different animal models of ethanol consumption (voluntary consumption, SA, and bingedrinking) the administration of CBD significantly reduced ethanol rewarding and the motivational actions that were associated with a reduction in the gene expression of $\mathrm{TH}$ in the VTA (Viudez-Martínez et al., 2018a; Viudez-Martinez et al., 2018b; Viudez-Martínez et al., 2020). Similarly, CBD significantly decreases $\mathrm{TH}$ in mice exposed to spontaneous cocaine withdrawal (Gasparyan et al., 2020). Nevertheless, in an animal model of spontaneous cannabinoid withdrawal CBD enhanced TH gene expression in the VTA (Navarrete et al., 2018). These apparent discrepancies could be explained by two main facts. First, DA synthesis and release vary throughout the different phases of the addictive process, depending on whether consumption or withdrawal stages are present. Second, DA release in the NAcc depends on the mechanism of action of each drug of abuse. Accordingly, cannabis, unlike alcohol and psychostimulants would present a minimal effect that could account for these opposite regulations (Nutt et al., 2015).

Thus, available evidence suggests that CBD may functionally regulate the activity of the mesolimbic DA system and counteract the effects of dysregulated dopaminergic transmission induced by drugs such as amphetamine, cocaine, alcohol, or cannabis. These findings could be related, at least in part, to the reduction of the reinforcing and motivational effects of these drugs, as well as to the regulation of the withdrawal syndrome. Nevertheless, more studies are needed to precisely explore CBD-mediated regulation of dopaminergic mechanisms involved in drug addiction.

\section{CBD and Opioidergic System}

The endogenous opioid system is closely involved in the regulation of addictive behaviors. Opioid peptides do not directly affect dopaminergic neurons function in the VTA but inhibit gamma-aminobutyric acid (GABAergic) interneurons that innervate VTA dopaminergic neurons in the mesolimbic system (Johnson and North, 1992). The activation of MOR in the VTA through its endogenous ligands, $\beta$-endorphin and enkephalin, disinhibits the inhibition produced by the GABAergic interneurons and increases DA release in the NAcc whereas the selective blockade of these receptors significantly decreases basal DA release (Spanagel et al., 1992). Some drugs of abuse (e.g., alcohol, cannabis) stimulate the release of endogenous opioids leading to a MOR-mediated increase of DA release in the NAcc (Tanda and Di Chiara, 1998).

The interaction between $\mathrm{CBD}$ and opioidergic system components has been barely explored. A few studies evaluated changes in the main targets of the opioidergic system after CBD administration. The first reference was published in 2006 by Kathmann et al. They described the CBD-mediated allosteric 
modulation of mu- and delta-opioid receptor by means of kinetic binding studies with ${ }^{3} \mathrm{H}-\mathrm{DAMGO}$ (D-Ala ${ }^{2}, \mathrm{NMePhe}^{4}$, Gly-ol) in the cerebral cortex membrane of male Wistar rats. These effects only occur at very high concentrations and cannot be expected to contribute to the in vivo action (Kathmann et al., 2006). Recently, our group analyzed MOR gene expression changes after CBD administration in animal models of alcohol addiction. Interestingly, CBD-induced reduction of voluntary ethanol consumption, ethanol SA and binge-drinking was associated with a down-regulation of MOR in the NAcc (ViudezMartínez et al., 2018a; Viudez-Martinez et al., 2018b; ViudezMartínez et al., 2020). Similarly, the administration of CBD normalized increased MOR gene expression in the NAcc in mice exposed to an animal model of spontaneous cannabinoid withdrawal (Navarrete et al., 2018). Therefore, independently of the experimental paradigm employed, the phase of addiction assessed and the drug, the effect of CBD was in the same direction. Thus, it is possible to speculate that CBD negatively modulates MOR; however, more studies should be carried out to further explore the specific interaction between CBD and MOR receptors, as well as with other components of the opioidergic system.

In summary, available evidence suggests that CBD-induced modulation of drug reinforcing and motivational properties could be mediated, at least in part, by the functional regulation of the opioidergic system. However, it remains to elucidate the precise mechanisms involved.

\section{CBD and Endogenous Cannabinoid System}

ECS is a ubiquitous lipid signaling system distributed throughout the organism that participates in multiple intracellular signaling pathways (Piomelli, 2003; Zou and Kumar, 2018). ECS regulates several physiological functions and mediates the crosstalk between different neurotransmitter systems, therefore, representing a key player in the control of behavioral responses (Katona and Freund, 2012; Atkinson and Abbott, 2018). CB1R and CB2R, endogenous ligands or endocannabinoids (AEA and 2-arachidonoylglycerol (2-AG)), and their synthesizing (N-acylphosphatidylethanolamine specific phospholipase D (NAPE-PLD) and diacylglycerol lipases (DAGL- $\alpha$ and DAGL- $\beta$ )) and degrading (FAAH and monoacylglycerol lipase (MAGL)) enzymes are the main components of the ECS, present in the central and peripheral nervous system (Mackie, 2005; Katona and Freund, 2012). As recently and extensively reviewed by our group and other authors, ECS is critically involved in the neurobiological substrate underlying drug addiction. Importantly, the functional localization of cannabinoid receptors in the mesocorticolimbic circuit participating in the modulation of the synthesis and release of dopamine is widely accepted (Maldonado et al., 2006; Parsons and Hurd, 2015; Sloan et al., 2017; Trigo and Le Foll, 2017; Manzanares et al., 2018).

Numerous studies were carried out to elucidate the interactive mechanisms between CBD and ECS components. One of the mechanisms is the inhibition of AEA hydrolysis and reuptake by blocking its catabolic enzyme (FAAH) and the corresponding membrane transporter, respectively (Bisogno et al., 2001;
Laprairie et al., 2015). Regarding the interaction with CB1R, CBD was first thought to be an antagonist (Thomas et al., 2007; Pertwee, 2008), but recent results suggested that CBD could act also as a non-competitive negative allosteric modulator of CB1R (Laprairie et al., 2015; Tham et al., 2019). Interestingly, a statistical meta-analysis of all present information describing direct effects of $\mathrm{CBD}$ at cannabinoid receptors concluded that there is no direct CBD-CB1R interaction that may account for the reported changes in endocannabinoid signaling (McPartland et al., 2015).

There is also controversy about the pharmacological effect of CBD on CB2R. It was proposed that CBD could act as a partial agonist (Tham et al., 2019), inverse agonist or even as an antagonist (Thomas et al., 2007). A recent report suggested that $\mathrm{CBD}$ might act as an allosteric modulator (MartinezPinilla et al., 2017). Finally, CBD presents recognized antagonistic properties on GPR55 receptor (Ryberg et al., 2007; Sharir and Abood, 2010; Ibeas Bih et al., 2015).

The findings published by our group demonstrated that CBD down-regulates the gene expression of CB1R and GPR55 whereas up-regulates $\mathrm{CB} 2 \mathrm{R}$ in the NAcc of $\mathrm{C} 57 \mathrm{BL} / 6 \mathrm{~J}$ mice exposed to models of cannabinoid withdrawal (Navarrete et al., 2018) and alcohol addiction (Viudez-Martínez et al., 2018a; Viudez-Martínez et al., 2020). These effects may be related, at least in part, with CBD-mediated improvement of withdrawal symptoms and the reduction of alcohol consumption, motivation, and relapse. Similarly, Ren et al. showed a reduction of CB1R gene and protein levels in the NAcc core and shell subregions of rats exposed to a cueinduced heroin seeking procedure. Interestingly, these authors suggested that the effects of CBD on CB1R expression would present a mesolimbic specificity (Ren et al., 2009). Furthermore, CBD increased CB1R protein expression in the HIPP of mice exposed to a cocaine SA paradigm (Luján et al., 2018). On the other hand, the antagonism of CB2R by the administration of AM630 completely blocked the reduction of cocaine SA by CBD, suggesting its critical involvement in CBD-mediated effects (Galaj et al., 2020).

Taken together, it is possible to argue that ECS components play a pivotal role in the actions of $\mathrm{CBD}$ on withdrawal-related, reinforcement, motivation or relapse induced by alcohol, cocaine, or heroin. Thus, a greater effort is essential to further characterize the mechanisms involving the ECS that underlies potential therapeutic effects of CBD in drug addiction.

\section{CBD and Serotonergic System}

The serotonergic system has a pivotal role in the modulation of motivational and reinforcement processes and is involved in the regulation of the rewarding effects of certain drugs of abuse. Mesolimbic dopaminergic neurons are critically regulated by serotonergic projections from the medial and dorsal raphe nuclei entailing an inhibitory control (Di Giovanni et al., 2010; Müller and Homberg, 2015). There are a high number of serotonergic receptors subtypes with different functional profiles, suggesting the complexity of serotonin-mediated regulation of drug reward. Among these, 5HT1a receptors 
stand out due to the large number of reports supporting its crucial role in drug addiction (Pinto et al., 2002; Risinger and Boyce, 2002; Müller et al., 2007; Kelaï et al., 2008; You et al., 2016). Importantly, $\mathrm{CBD}$ is known to act as a positive allosteric modulator at 5HT1a receptors (Russo et al., 2005; Campos and Guimarães, 2008) and this mechanism is closely involved in its anxiolytic and antidepressant actions (Fogaça et al., 2014; Linge et al., 2016; Sartim et al., 2016). Furthermore, the modulation of dopamine release in the NAcc by CBD was described and it appears to occur through a mechanism involving the activation of 5HT1a receptors (Norris et al., 2016).

To investigate the role of $5 \mathrm{HT} 1 \mathrm{a}$ receptors in the CBDmediated regulation of drug reward, our group analyzed the gene expression in the dorsal raphe (DR) of $\mathrm{C} 57 \mathrm{BL} / 6 \mathrm{~J}$ mice that underwent an ethanol SA paradigm. Interestingly, the reduction in ethanol consumption and motivation induced by CBD was accompanied by a reduction of $5 \mathrm{HT} 1 \mathrm{a}$ gene expression (Viudez-Martínez et al., 2018b). Pharmacological approaches employing the 5HT1a antagonist WAY-100635 confirmed the involvement of this receptor in the effects of $\mathrm{CBD}$ on druginduced reward. First, intra-dorsal raphe injection of WAY100635 abolished the CBD-mediated inhibition of the rewardfacilitating effect of morphine measured in the ICSS paradigm (Katsidoni et al., 2013). Second, the administration of the selective 5HT1a antagonist completely blocked CBD plus naltrexone effects on ethanol SA (Viudez-Martínez et al., 2018b). Third, blockade of 5HT1a receptors attenuated $\mathrm{CBD}$-mediated reduction of cocaine SA (Galaj et al., 2020). Therefore, all these results suggest that the effects of $\mathrm{CBD}$ on drug reward and motivation are mediated, at least in part, by $5 \mathrm{HT} 1 \mathrm{a}$ receptors. It is tempting to hypothesize that the activation of these receptors by CBD in brain areas of the mesocorticolimbic circuit may play a critical role. A great effort is necessary to further elucidate and understand the interaction of CBD with the serotonergic system and its involvement in drug addiction.

\section{CBD and Glutamatergic System}

Glutamate $(\mathrm{Glu})$ is the main excitatory neurotransmitter of the central nervous system. Glutamatergic synaptic plasticity in the mesocorticolimbic dopaminergic circuit is a key neuronal process in appetitive learning and significantly contributes to the development and maintenance of drug addiction (Yamaguchi et al., 2011; van Huijstee and Mansvelder, 2014). Drugs of abuse trigger critical adaptive changes in the reward system by inducing widespread modifications of glutamatergic synapses. The NAcc receives glutamatergic projections from the VTA (Yamaguchi et al., 2011) and other regions involved in the addictive process such as PFC, amygdala, and HIPP (Koob and Volkow, 2010; Floresco, 2015; Heinsbroek et al., 2020). The acquisition of drug reward associations depends on the convergence of dopaminergic and glutamatergic signaling in the NAcc (Neuhofer et al., 2019). Thus, glutamatergic neurotransmission plays an important role in the functional regulation of relevant brain structures involved in the neurocircuitry of drug addiction.

Few studies evaluated the effects of CBD on the different components of glutamatergic signaling in drug reward in animal models of addiction. The administration of CBD inhibited cue- induced heroin seeking in an intravenous SA paradigm and increased AMPA GluR1 protein levels in the NAcc core and shell subregions, achieving a normalization effect. However, mGluR5 protein levels were not modified by CBD (Ren et al., 2009). Also, CBD significantly reduced AMPA GluR1/2 protein levels in the striatum of mice self-administering cocaine (Luján et al., 2018). Finally, in an animal model of cocaine-induced intoxication, the administration of CBD reduced cocaine-induced seizures and this effect was associated with the activation of the mTor pathway with a subsequent significant reduction on Glu release in hippocampal synaptosomes (Gobira et al., 2015).

Therefore, although the available information is very limited, it is reasonable to suggest that CBD-mediated regulation of glutamatergic neurotransmission plays a crucial role in the modulation not only of drug reward but also of drug-induced neuroadaptive changes. However, more studies are needed to confirm this notion and to explore the effects of CBD in other targets of the glutamatergic system.

\section{CBD and Hippocampal Neurogenesis}

In recent years, the major role of hippocampal neurogenesis in the addictive process has become increasingly established (Mandyam and Koob, 2012; Chambers, 2013; DerocheGamonet et al., 2019). A number of reports suggests that psychoactive substances with addictive potential modify neurogenesis in the adult HIPP (Castilla-Ortega et al., 2016). The subventricular zone (SVZ) and the subgranular layer of the hippocampal dentate gyrus (DG) are the brain regions where adult neurogenesis occurs. Drugs such as psychomotor stimulants, opioids or alcohol significantly impair several aspects of adult neurogenesis including the rate of progenitor proliferation, the survival of newly generated cells and the maturation and acquisition of cellular phenotype (GarcíaFuster et al., 2010; Taffe et al., 2010). These alterations may affect several drug-related psychological processes such as learning, memory and mood regulation (Canales, 2007).

One of the first reports showing the pro-neurogenic effect of CBD was published by Wolf et al.. The treatment with CBD (6 weeks) enhanced adult neurogenesis; however, this effect was not present in mice lacking CB1R suggesting the critical role of these receptors in the CBD-mediated actions on hippocampal neurogenesis (Wolf et al., 2010). The anxiolytic actions of CBD in mice exposed to chronic unpredictable stress were closely associated with the pro-neurogenic effect of CBD. The authors suggested that this phenomenon depends on the facilitation of the endocannabinoid-mediated signaling and subsequent cannabinoid receptors activation (Campos et al., 2013; Fogaça et al., 2018). Likewise, repeated administration of CBD at low doses (3 mg/kg, i.p.) increased cell proliferation and neurogenesis in the DG and SVZ (Schiavon et al., 2016). Interestingly, a recent critical review covers the potential therapeutic implications of the pro-neurogenic effects of CBD for the treatment of distinct psychiatric disorders, including drug addiction (Lujan and Valverde, 2020).

Recent advances focused on the study of the molecular basis that underlies the neurogenesis promoting actions of CBD in relation with the regulation or drug reward. Lujan et al. described 
that CBD increased neural progenitor proliferation in the HIPP of cocaine self-administering animals. They explored the activation of MAPK pathway and its downstream pathways that regulate the expression of the transcriptional (CREB) and neurotrophic (BDNF) factors, responsible for the levels of neuronal hippocampal proliferation. Interestingly, the administration of CBD up-regulated ERK1/2 and CREB phosphorylation, as well as BDNF expression in the HIPP of mice that underwent cocaine SA. Furthermore, the number of BrdU/NeuN stained cells in the HIPP was significantly higher in CBD-treated animals (Luján et al., 2018). To further confirm the involvement of adult hippocampal neurogenesis in the CBD-mediated actions on cocaine reward, Lujan et al. carried out an elegant study administering temozolomide ( $25 \mathrm{mg} / \mathrm{kg} /$ day $)$, a chemotherapy drug that blocks hippocampal neurogenesis. The results clearly demonstrated that in absence of the neurogenesis processes CBD does not modulate cocaine consumption and motivation (Luján et al., 2019). Thus, additional studies are warranted to further explore the therapeutic potential of CBD in addictive disorders regarding its pro-neurogenic as well as neuroprotective properties.

\section{CONCLUDING REMARKS}

The present review shows the current state of the art about the potential interest of $\mathrm{CBD}$ as a new pharmacological avenue for SUD. According to the findings from preclinical and clinical studies, CBD alone or in combination with commonly employed treatment strategies in drug addiction may configure a potential therapeutic option for improving the dishabituation process of addicted patients.

The great interest in the promising profile of CBD for the management of SUD was revealed by the significant number of clinical studies published or currently underway. One of the most representative examples is CUD for which numerous clinical trials evaluated the effects of $\mathrm{CBD}$, mostly in combination with THC, on withdrawal symptoms, craving, and cannabis use. The information with CBD alone is still insufficient due to the small number of patients in the studies that were carried out to date. Additional clinical trials with more patients and longer treatment periods are warranted to further explore the efficacy and safety of CBD for the treatment of CUD. Interestingly, the results reported by our group in an animal model of spontaneous cannabinoid withdrawal support the implementation of randomized controlled trials (RCT) using only CBD. In addition, variables like motivation, reinforcement, withdrawal, relapse, and retention in treatment should be considered for a global overview during treatment for CUD. Smoking is another SUD in which clinical studies were predominantly conducted to evaluate CBD actions. Nevertheless, more information is required to accurately assess the therapeutic role that $\mathrm{CBD}$ could have in smoking cessation. Importantly, one of the main current limitations is the low oral bioavailability of CBD that requires the joint effort to develop new oral formulations to ensure adequate plasma levels and consequently reduce

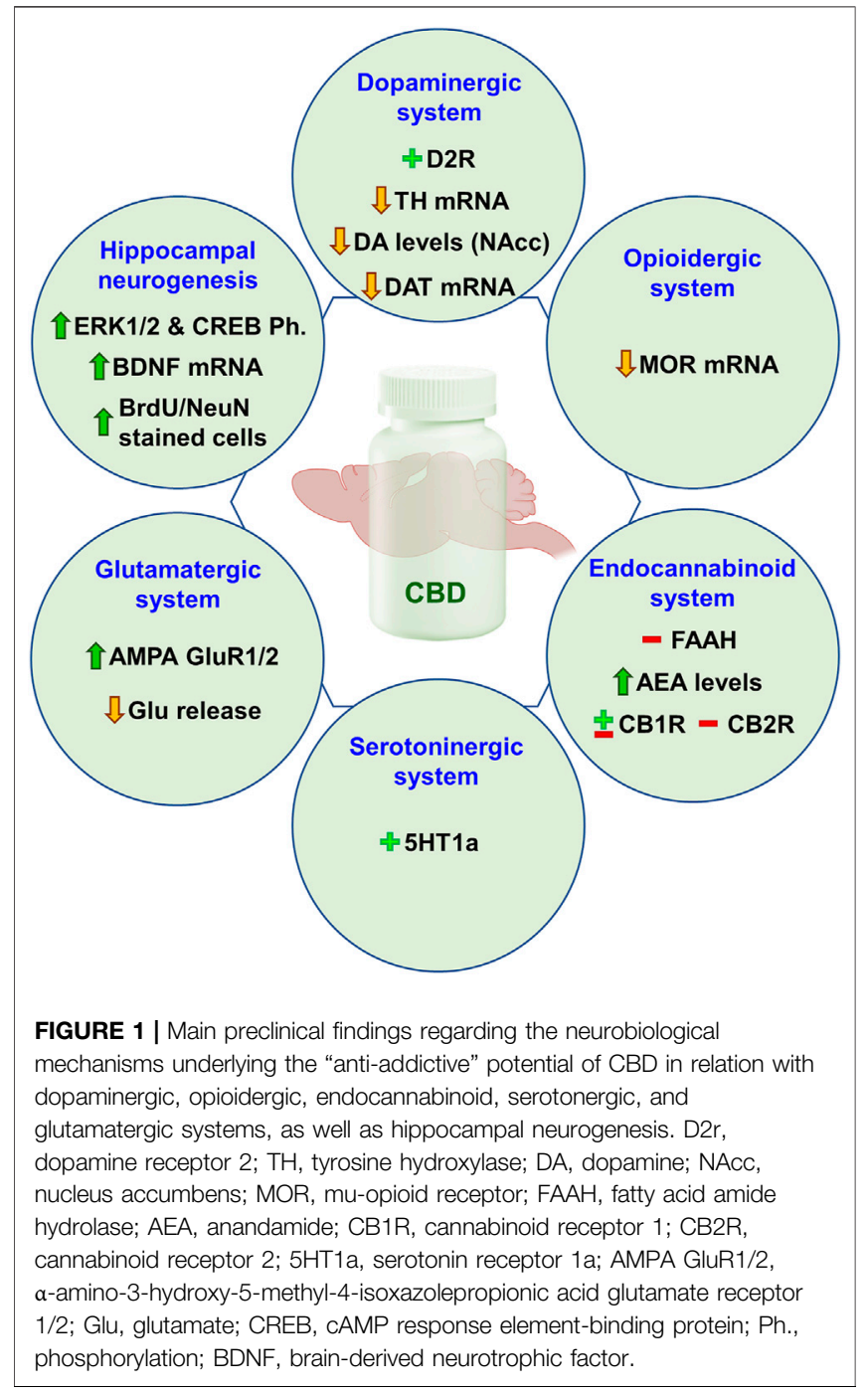

pharmacokinetic variability (Millar et al., 2018; Izgelov et al., 2020; Perucca and Bialer, 2020).

On the other hand, the role of CBD in alcohol, opioid and psychostimulant use disorders lies mainly in the studies carried out with different animal models, which in turn motivated the performance of several ongoing clinical trials. The findings included in this review suggest that CBD may reduce the consumption, motivation or relapse of alcohol, opioids (i.e., heroin, morphine) and psychostimulants (amphetamine, methamphetamine, and cocaine), as well as the withdrawal-related signs of morphine and cocaine. The clinical trials recently launched will provide relevant information to know the outcome of the translational approach to patients suffering from these addictive disorders. In addition, it is important to highlight the protective actions derived from CBD treatment not only to attenuate drug-induced damages in the CNS, but also in peripheral tissues such as alcohol-induced liver steatosis or cirrhosis. 
A fundamental aspect to optimize the therapeutic potential of CBD in the treatment of SUD is to improve our knowledge about the mechanisms that are involved in its actions. For that reason, the present review dedicates a special section to the interaction between $\mathrm{CBD}$ and distinct neurotransmission or functional regulation systems (Figure 1). Taking into account all the information that has been collected in this respect, the following ideas can be highlighted: 1) CBD can modulate dopaminergic neurotransmission in the mesolimbic circuit through the direct regulation of dopamine synthesis, release or effects on dopamine receptors, or by indirect mechanisms as the modulation of MOR; 2) the ECS plays a pivotal role in CBDmediated effects on drug reward, involving the regulation of endocannabinoid signaling through the alteration of AEA levels and CB1R or CB2R function; 3) 5HT1a receptors are critically involved in the effects of $\mathrm{CBD}$ on drug addiction; and 4) hippocampal neurogenesis appears to be essential for the regulation of cocaine consumption and motivation by CBD.

In summary, we have ahead of us an exciting race to discover how CBD could contribute to the area of drug addiction from a therapeutic point of view. More preclinical and clinical studies are necessary to further evaluate the role of $\mathrm{CBD}$ as a new therapeutic intervention for SUD. In this regard, it is relevant to emphasize that according to the multiple pharmacological profile of CBD accounting for the anxiolytic, antidepressant or antipsychotic properties, comorbid clinical entities such as anxiety, depression or psychotic disorders could be also successfully managed. Importantly, taking into consideration

\section{REFERENCES}

Adams, R. (1942). Marihuana: Harvey Lecture, February 19, 1942. Bull. N. Y Acad. Med. $18,705-730$

Allsop, D. J., Copeland, J., Lintzeris, N., Dunlop, A. J., Montebello, M., Sadler, C., et al. (2014). Nabiximols as an Agonist Replacement Therapy during Cannabis Withdrawal. JAMA psychiatry 71, 281-291. doi:10.1001/jamapsychiatry.2013. 3947

Allsop, D., Lintzeris, N., Copeland, J., Dunlop, A., and McGregor, I. (2015). Cannabinoid Replacement Therapy (CRT): Nabiximols (Sativex) as a Novel Treatment for Cannabis Withdrawal. Clin. Pharmacol. Ther. 97, 571-574. doi:10.1002/cpt.109

Andersson, H. W., Wenaas, M., and Nordfjærn, T. (2019). Relapse after Inpatient Substance Use Treatment: A Prospective Cohort Study Among Users of Illicit Substances. Addict. Behaviors 90, 222-228. doi:10.1016/j.addbeh.2018.11.008

Andre, C. M., Hausman, J. F., and Guerriero, G. (2016). Cannabis Sativa: The Plant of the Thousand and One Molecules. Front. Plant Sci. 7, 19. doi:10.3389/fpls. 2016.00019

APA (2013). Diagnostic and Statistical Manual of Mental Disorders. 5th edn.. Washington, D.C.: DSM-V, American Psychiatric Association (APA).

Aracil-Fernández, A., Almela, P., and Manzanares, J. (2013). Pregabalin and Topiramate Regulate Behavioural and Brain Gene Transcription Changes Induced by Spontaneous Cannabinoid Withdrawal in Mice. Addict. Biol. 18, 252-262. doi:10.1111/j.1369-1600.2011.00406.x

Aso, E., Fernández-Dueñas, V., López-Cano, M., Taura, J., Watanabe, M., Ferrer, I., et al. (2019). Adenosine A2A-Cannabinoid CB1 Receptor Heteromers in the Hippocampus: Cannabidiol Blunts $\Delta 9$-Tetrahydrocannabinol-Induced Cognitive Impairment. Mol. Neurobiol. 56, 5382-5391. doi:10.1007/s12035018-1456-3

Atkinson, D. L., and Abbott, J. K. (2018). Cannabinoids and the Brain: The Effects of Endogenous and Exogenous Cannabinoids on Brain Systems and Function, the sex biological differences in terms of brain function and connectivity and its relationship with distinct vulnerability to develop a substance use disorder (Becker et al., 2017), it could be argued that $\mathrm{CBD}$ may display differential effects depending on sex (Viudez-Martínez et al., 2020), an aspect that needs to be further explored. The clinical studies that are currently underway will provide relevant information to improve our knowledge about the efficacy and safety of CBD for the treatment of SUD.

\section{AUTHOR CONTRIBUTIONS}

FN and JM designed the sections and contents of the review article. FN oversaw the organization to distribute the writing tasks among the authors and participated in article writing. MSSG, AG, and $\mathrm{AO}$ perform the literature searches and participated in the article writing. All the authors critically reviewed and approved the final version of the article.

\section{FUNDING}

The preparation of the manuscript was supported by "Instituto de Salud Carlos III, Fondos FEDER, Red de Trastornos Adictivos" (RTA, RD16/0017/0014 to J.M.) and "Ministerio de Sanidad, Delegación del Gobierno para el Plan Nacional Sobre Drogas" (PNSD, 2019I012 to J.M.). the Complex Connection between Cannabis and Schizophrenia. Academic Press, 37-74. doi:10.1016/b978-0-12-804791-0.00003-3Cannabinoids and the Brain: The Effects of Endogenous and Exogenous Cannabinoids on Brain Systems and Function

Babalonis, S., Haney, M., Malcolm, R. J., Lofwall, M. R., Votaw, V. R., Sparenborg, S., et al. (2017). Oral Cannabidiol Does Not Produce a Signal for Abuse Liability in Frequent Marijuana Smokers. Drug and Alcohol Dependence 172, 9-13. doi:10.1016/j.drugalcdep.2016.11.030

Beale, C., Broyd, S. J., Chye, Y., Suo, C., Schira, M., Galettis, P., et al. (2018). Prolonged Cannabidiol Treatment Effects on Hippocampal Subfield Volumes in Current Cannabis Users. Cannabis Cannabinoid Res. 3, 94-107. doi:10.1089/ can.2017.0047

Becker, J. B., McClellan, M. L., and Reed, B. G. (2017). Sex Differences, Gender and Addiction. J. Neurosci. Res. 95, 136-147. doi:10.1002/jnr.23963

Bell, J. (2014). Pharmacological Maintenance Treatments of Opiate Addiction. Br. J. Clin. Pharmacol. 77, 253-263. doi:10.1111/bcp.12051

Bergamaschi, M. M., Queiroz, R. H., Zuardi, A. W., and Crippa, J. A. (2011). Safety and Side Effects of Cannabidiol, a Cannabis Sativa Constituent. Curr. Drug Saf. 6, 237-249. doi:10.2174/157488611798280924

Bhardwaj, A. K., Allsop, D. J., Copeland, J., McGregor, I. S., Dunlop, A., Shanahan, M., et al. (2018). Replacement for Cannabis Dependence Study, Randomised Controlled Trial (RCT) of Cannabinoid Replacement Therapy (Nabiximols) for the Management of Treatment-Resistant Cannabis Dependent Patients: a Study Protocol. BMC Psychiatry 18, 140. doi:10.1186/s12888-018-1682-2

Bhargava, H. N. (1976). Effect of Some Cannabinoids on Naloxone-Precipitated Abstinence in Morphine-dependent Mice. Psychopharmacol. 49, 267-270. doi:10.1007/bf00426828

Bisogno, T., Hanuš, L., De Petrocellis, L., Tchilibon, S., Ponde, D. E., Brandi, I., et al. (2001). Molecular Targets for Cannabidiol and its Synthetic Analogues: Effect on Vanilloid VR1 Receptors and on the Cellular Uptake and Enzymatic Hydrolysis of Anandamide. Br. J. Pharmacol. 134, 845-852. doi:10.1038/sj. bjp. 0704327 
Blessing, E. M., Steenkamp, M. M., Manzanares, J., and Marmar, C. R. (2015). Cannabidiol as a Potential Treatment for Anxiety Disorders. Neurotherapeutics 12, 825-836. doi:10.1007/s13311-015-0387-1

Brezing, C. A., and Levin, F. R. (2018). The Current State of Pharmacological Treatments for Cannabis Use Disorder and Withdrawal. Neuropsychopharmacol. 43, 173-194. doi:10.1038/npp.2017.212

Budney, A. J., and Hughes, J. R. (2006). The Cannabis Withdrawal Syndrome. Curr. Opin. Psychiatry 19, 233-238. doi:10.1097/01.yco.0000218592.00689.e5

Budney, A. J., Vandrey, R. G., Hughes, J. R., Moore, B. A., and Bahrenburg, B. (2007). Oral Delta-9-Tetrahydrocannabinol Suppresses Cannabis Withdrawal Symptoms. Drug and Alcohol Dependence 86, 22-29. doi:10.1016/j.drugalcdep. 2006.04.014

Burns, L., Gisev, N., Larney, S., Dobbins, T., Gibson, A., Kimber, J., et al. (2015). A Longitudinal Comparison of Retention in Buprenorphine and Methadone Treatment for Opioid Dependence in New South Wales, Australia. Addiction 110, 646-655. doi:10.1111/add.12834

Calpe-Lopez, C., Gasparyan, A., Navarrete, F., Manzanares, J., Miñarro, J., and Aguilar, M. A. (2020). Cannabidiol Prevents Priming- and Stress-Induced Reinstatement of the Conditioned Place Preference Induced by Cocaine in Mice. J. Psychopharmacol. 9, 269881120965952. (in press). doi:10.1177/ 0269881120965952

Campolongo, P., and Trezza, V. (2012). The Endocannabinoid System: a Key Modulator of Emotions and Cognition. Front. Behav. Neurosci. 6, 73. doi:10. 3389/fnbeh.2012.00073

Campos, A. C., Ferreira, F. R., and Guimarães, F. S. (2012). Cannabidiol Blocks Long-Lasting Behavioral Consequences of Predator Threat Stress: Possible Involvement of 5HT1A Receptors. J. Psychiatr. Res. 46, 1501-1510. doi:10. 1016/j.jpsychires.2012.08.012

Campos, A. C., and Guimarães, F. S. (2008). Involvement of 5HT1A Receptors in the Anxiolytic-like Effects of Cannabidiol Injected into the Dorsolateral Periaqueductal Gray of Rats. Psychopharmacol. 199, 223-230. doi:10.1007/ s00213-008-1168-x

Campos, A. C., Ortega, Z., Palazuelos, J., Fogaça, M. V., Aguiar, D. C., Díaz-Alonso, J., et al. (2013). The Anxiolytic Effect of Cannabidiol on Chronically Stressed Mice Depends on Hippocampal Neurogenesis: Involvement of the Endocannabinoid System. Int. J. Neuropsychopharmacol. 16, 1407-1419. doi:10.1017/s1461145712001502

Canales, J. J. (2007). Adult Neurogenesis and the Memories of Drug Addiction. Eur. Arch. Psychiatry Clin. Neurosc. 257, 261-270. doi:10.1007/s00406-0070730-6

Carlini, E. A., and Cunha, J. M. (1981). Hypnotic and Antiepileptic Effects of Cannabidiol. J. Clin. Pharmacol. 21, 417S-427S. doi:10.1002/j.1552-4604.1981. tb02622.x

Carrier, E. J., Auchampach, J. A., and Hillard, C. J. (2006). Inhibition of an Equilibrative Nucleoside Transporter by Cannabidiol: a Mechanism of Cannabinoid Immunosuppression. Proc. Natl. Acad. Sci. 103, 7895-7900. doi:10.1073/pnas.0511232103

Castilla-Ortega, E., Serrano, A., Blanco, E., Araos, P., Suárez, J., Pavón, F. J., et al. (2016). A Place for the hippocampus in the Cocaine Addiction Circuit: Potential Roles for Adult Hippocampal Neurogenesis. Neurosci. Biobehavioral Rev. 66, 15-32. doi:10.1016/j.neubiorev.2016.03.030

Chagas, M. H. N., Zuardi, A. W., Tumas, V., Pena-Pereira, M. A., Sobreira, E. T., Bergamaschi, M. M., et al. (2014). Effects of Cannabidiol in the Treatment of Patients with Parkinson's Disease: an Exploratory DoubleBlind Trial. J. Psychopharmacol. 28, 1088-1098. doi:10.1177/ 0269881114550355

Chambers, R. A. (2013). Adult Hippocampal Neurogenesis in the Pathogenesis of Addiction and Dual Diagnosis Disorders. Drug and Alcohol Dependence 130, 1-12. doi:10.1016/j.drugalcdep.2012.12.005

Chandra, S., Radwan, M. M., Majumdar, C. G., Church, J. C., Freeman, T. P., and ElSohly, M. A. (2019). New Trends in Cannabis Potency in United States and Europe during the Last Decade (2008-2017). Eur. Arch. Psychiatry Clin. Neurosci. 269, 5-15. doi:10.1007/s00406-019-00983-5

Cheng, D., Spiro, A. S., Jenner, A. M., Garner, B., and Karl, T. (2014). Long-term Cannabidiol Treatment Prevents the Development of Social Recognition Memory Deficits in Alzheimer's Disease Transgenic Mice. Jad 42, 1383-1396. doi:10.3233/jad-140921
Chesher, G. B., and Jackson, D. M. (1985). The Quasi-Morphine Withdrawal Syndrome: Effect of Cannabinol, Cannabidiol and Tetrahydrocannabinol. Pharmacol. Biochem. Behav. 23, 13-15. doi:10.1016/0091-3057(85)90122-4

Chesworth, R., and Karl, T. (2020). Cannabidiol (CBD) Reduces CocaineEnvironment Memory in Mice. Pharmacol. Biochem. Behav. 199, 173065. doi:10.1016/j.pbb.2020.173065

Cicero, T. J., Ellis, M. S., and Kasper, Z. A. (2017). Increased Use of Heroin as an Initiating Opioid of Abuse. Addict. Behaviors 74, 63-66. doi:10.1016/j.addbeh. 2017.05.030

Collaborators, G. B. D. A. (2018). Alcohol Use and Burden for 195 Countries and Territories, 1990-2016: a Systematic Analysis for the Global Burden of Disease Study 2016. Lancet 392, 1015-1035. doi:10.1016/S0140-6736(18)31310-2

Crippa, J. A. S., Hallak, J. E. C., Machado-de-Sousa, J. P., Queiroz, R. H. C., Bergamaschi, M., Chagas, M. H. N., et al. (2013). Cannabidiol for the Treatment of Cannabis Withdrawal Syndrome: a Case Report. J. Clin. Pharm. Ther. 38, 162-164. doi:10.1111/jcpt.12018

de Carvalho, C. R., and Takahashi, R. N. (2017). Cannabidiol Disrupts the Reconsolidation of Contextual Drug-Associated Memories in Wistar Rats. Addict. Biol. 22, 742-751. doi:10.1111/adb.12366

De Ternay, J., Naassila, M., Nourredine, M., Louvet, A., Bailly, F., Sescousse, G., et al. (2019). Therapeutic Prospects of Cannabidiol for Alcohol Use Disorder and Alcohol-Related Damages on the Liver and the Brain. Front. Pharmacol. 10, 627. doi:10.3389/fphar.2019.00627

Degenhardt, L., Charlson, F., Ferrari, A., Santomauro, D., Erskine, H., MantillaHerrara, A., et al. (2018). The Global Burden of Disease Attributable to Alcohol and Drug Use in 195 Countries and Territories, 1990-2016: a Systematic Analysis for the Global Burden of Disease Study 2016. The Lancet Psychiatry 5, 987-1012. doi:10.1016/s2215-0366(18)30337-7

Deroche-Gamonet, V., Revest, J.-M., Fiancette, J.-F., Balado, E., Koehl, M., Grosjean, N., et al. (2019). Depleting Adult Dentate Gyrus Neurogenesis Increases Cocaine-Seeking Behavior. Mol. Psychiatry 24, 312-320. doi:10. 1038/s41380-018-0038-0

Devinsky, O., Cilio, M. R., Cross, H., Fernandez-Ruiz, J., French, J., Hill, C., et al. (2014). Cannabidiol: Pharmacology and Potential Therapeutic Role in Epilepsy and Other Neuropsychiatric Disorders. Epilepsia 55, 791-802. doi:10.1111/epi. 12631

Devinsky, O., Marsh, E., Friedman, D., Thiele, E., Laux, L., Sullivan, J., et al. (2016). Cannabidiol in Patients with Treatment-Resistant Epilepsy: an Open-Label Interventional Trial. Lancet Neurol. 15, 270-278. doi:10.1016/s1474-4422(15) 00379-8

Di Giovanni, G., Esposito, E., and Di Matteo, V. (2010). Role of Serotonin in Central Dopamine Dysfunction. CNS Neurosci. Ther. 16, 179-194. doi:10.1111/ j.1755-5949.2010.00135.x

Durazzo, T. C., and Meyerhoff, D. J. (2017). Psychiatric, Demographic, and Brain Morphological Predictors of Relapse after Treatment for an Alcohol Use Disorder. Alcohol. Clin. Exp. Res. 41, 107-116. doi:10.1111/acer.13267

Englund, A., Morrison, P. D., Nottage, J., Hague, D., Kane, F., Bonaccorso, S., et al. (2013). Cannabidiol Inhibits THC-Elicited Paranoid Symptoms and Hippocampal-dependent Memory Impairment. J. Psychopharmacol. 27, 19-27. doi:10.1177/0269881112460109

Filev, R., Engelke, D. S., Da Silveira, D. X., Mello, L. E., and Santos-Junior, J. G. (2017). THC Inhibits the Expression of Ethanol-Induced Locomotor Sensitization in Mice. Alcohol 65, 31-35. doi:10.1016/j.alcohol.2017.06.004

Floresco, S. B. (2015). The Nucleus Accumbens: an Interface between Cognition, Emotion, and Action. Annu. Rev. Psychol. 66, 25-52. doi:10.1146/annurevpsych-010213-115159

Fogaça, M. V., Campos, A. C., Coelho, L. D., Duman, R. S., and Guimarães, F. S. (2018). The Anxiolytic Effects of Cannabidiol in Chronically Stressed Mice Are Mediated by the Endocannabinoid System: Role of Neurogenesis and Dendritic Remodeling. Neuropharmacol. 135, 22-33. doi:10.1016/j.neuropharm.2018.03.001

Fogaça, M. V., Reis, F. M. C. V., Campos, A. C., and Guimarães, F. S. (2014). Effects of Intra-prelimbic Prefrontal Cortex Injection of Cannabidiol on Anxiety-like Behavior: Involvement of 5HT1A Receptors and Previous Stressful Experience. Eur. Neuropsychopharmacol. 24, 410-419. doi:10.1016/j.euroneuro.2013.10.012 Freeman, A. M., Petrilli, K., Lees, R., Hindocha, C., Mokrysz, C., Curran, H. V., et al. (2019a). How Does Cannabidiol (CBD) Influence the Acute Effects of Delta-9-Tetrahydrocannabinol (THC) in Humans? A Systematic Review. 
Neurosci. Biobehavioral Rev. 107, 696-712. doi:10.1016/j.neubiorev.2019. 09.036

Freeman, T. P., Groshkova, T., Cunningham, A., Sedefov, R., Griffiths, P., and Lynskey, M. T. (2019b). Increasing Potency and Price of Cannabis in Europe, 2006-16. Addiction 114, 1015-1023. doi:10.1111/add.14525

Freeman, T. P., Hindocha, C., Baio, G., Shaban, N. D. C., Thomas, E. M., Astbury, D., et al. (2020). Cannabidiol for the Treatment of Cannabis Use Disorder: a Phase 2a, Double-Blind, Placebo-Controlled, Randomised, Adaptive Bayesian Trial. Lancet Psychiatry 7, 865-874. doi:10.1016/S2215-0366(20)30290-X

French, E. D., Dillon, K., and Wu, X. (1997). Cannabinoids Excite Dopamine Neurons in the Ventral Tegmentum and Substantia Nigra. Neuroreport 8, 649-652. doi:10.1097/00001756-199702100-00014

Galaj, E., Bi, G.-H., Yang, H.-J., and Xi, Z.-X. (2020). Cannabidiol Attenuates the Rewarding Effects of Cocaine in Rats by CB2, 5-HT1A and TRPV1 Receptor Mechanisms. Neuropharmacol. 167, 107740. doi:10.1016/j.neuropharm.2019.107740

Gaoni, Y., and Mechoulam, R. (1964). Isolation, Structure, and Partial Synthesis of an Active Constituent of Hashish. J. Am. Chem. Soc. 86 (8), 1646-1647. doi:10. 1021/ja01062a046

García-Fuster, M. J., Perez, J. A., Clinton, S. M., Watson, S. J., and Akil, H. (2010). Impact of Cocaine on Adult Hippocampal Neurogenesis in an Animal Model of Differential Propensity to Drug Abuse. Eur. J. Neurosci. 31, 79-89. doi:10.1111/ j.1460-9568.2009.07045.x

García-Gutiérrez, M. S., Navarrete, F., Viudez-Martínez, A., Gasparyan, A., Caparros, E., and Manzanares, J. (2018). "Cannabidiol and Cannabis Use Disorders," in Cannabis Use Disorders. Editors I. D. Montoya and S. R. B. Weiss (Springer).

Gasparyan, A., Navarrete, F., Rodríguez-Arias, M., Miñarro, J., and Manzanares, J. (2020). Effects of Cannabidiol on Behavioural and Gene Expression Changes Induced by Spontaneous Cocaine Withdrawal. Neurotherapeutics. (in press). doi:10.1007/s13311-020-00976-6

Gbd 2017 Disease and Injury Incidence and Prevalence Collaborators (2018). Global, Regional, and National Incidence, Prevalence, and Years Lived with Disability for 354 Diseases and Injuries for 195 Countries and Territories, 19902017: a Systematic Analysis for the Global Burden of Disease Study 2017. Lancet 392, 1789-1858. doi:10.1016/S0140-6736(18)32279-7

Giacoppo, S., Soundara Rajan, T., Galuppo, M., Pollastro, F., Grassi, G., Bramanti, P., et al. (2015). Purified Cannabidiol, the Main Non-psychotropic Component of Cannabis Sativa, Alone, Counteracts Neuronal Apoptosis in Experimental Multiple Sclerosis. Eur. Rev. Med. Pharmacol. Sci. 19, 4906-4919.

Giacoppo, S., Bramanti, P., and Mazzon, E. (2017). Sativex in the Management of Multiple Sclerosis-Related Spasticity: An Overview of the Last Decade of Clinical Evaluation. Mult. Scler. Relat. Disord. 17, 22-31. doi:10.1016/j. msard.2017.06.015

Gobira, P. H., Vilela, L. R., Gonçalves, B. D. C., Santos, R. P. M., de Oliveira, A. C., Vieira, L. B., et al. (2015). Cannabidiol, a Cannabis Sativa Constituent, Inhibits Cocaine-Induced Seizures in Mice: Possible Role of the mTOR Pathway and Reduction in Glutamate Release. Neurotoxicol. 50, 116-121. doi:10.1016/j. neuro.2015.08.007

Gonzalez-Cuevas, G., Martin-Fardon, R., Kerr, T. M., Stouffer, D. G., Parsons, L. H., Hammell, D. C., et al. (2018). Unique Treatment Potential of Cannabidiol for the Prevention of Relapse to Drug Use: Preclinical Proof of Principle. Neuropsychopharmacol 43, 2036-2045. doi:10.1038/s41386-018-0050-8

Gorelick, D. A., Levin, K. H., Copersino, M. L., Heishman, S. J., Liu, F., Boggs, D. L., et al. (2012). Diagnostic Criteria for Cannabis Withdrawal Syndrome. Drug and Alcohol Dependence 123, 141-147. doi:10.1016/j.drugalcdep.2011.11.007

Gorodetzky, C. W., Walsh, S. L., Martin, P. R., Saxon, A. J., Gullo, K. L., and Biswas, K. (2017). A Phase III, Randomized, Multi-Center, Double Blind, Placebo Controlled Study of Safety and Efficacy of Lofexidine for Relief of Symptoms in Individuals Undergoing Inpatient Opioid Withdrawal. Drug and Alcohol Dependence 176, 79-88. doi:10.1016/j.drugalcdep.2017.02.020

Grant, B. F., Goldstein, R. B., Saha, T. D., Chou, S. P., Jung, J., Zhang, H., et al. (2015). Epidemiology ofDSM-5Alcohol Use Disorder. JAMA Psychiatry 72, 757-766. doi:10.1001/jamapsychiatry.2015.0584

Guimarães, F. S., Chiaretti, T. M., Graeff, F. G., and Zuardi, A. W. (1990). Antianxiety Effect of Cannabidiol in the Elevated Plus-Maze. Psychopharmacol. 100, 558-559. doi:10.1007/bf02244012

Guo, S., Manning, V., Yang, Y., Koh, P. K., Chan, E., de Souza, N. N., et al. (2018). Lofexidine versus Diazepam for the Treatment of Opioid Withdrawal
Syndrome: A Double-Blind Randomized Clinical Trial in Singapore. J. Substance Abuse Treat. 91, 1-11. doi:10.1016/j.jsat.2018.04.012

Hamelink, C., Hampson, A., Wink, D. A., Eiden, L. E., and Eskay, R. L. (2005). Comparison of Cannabidiol, Antioxidants, and Diuretics in Reversing Binge Ethanol-Induced Neurotoxicity. J. Pharmacol. Exp. Ther. 314, 780-788. doi:10. 1124/jpet.105.085779

Haney, M., Cooper, Z. D., Bedi, G., Vosburg, S. K., Comer, S. D., and Foltin, R. W. (2013). Nabilone Decreases Marijuana Withdrawal and a Laboratory Measure of Marijuana Relapse. Neuropsychopharmacol 38, 1557-1565. doi:10.1038/npp. 2013.54

Haney, M., Hart, C. L., Vosburg, S. K., Comer, S. D., Reed, S. C., and Foltin, R. W. (2008). Effects of THC and Lofexidine in a Human Laboratory Model of Marijuana Withdrawal and Relapse. Psychopharmacol. 197, 157-168. doi:10. 1007/s00213-007-1020-8

Haney, M., Hart, C. L., Vosburg, S. K., Nasser, J., Bennett, A., Zubaran, C., et al. (2004). Marijuana Withdrawal in Humans: Effects of Oral THC or Divalproex. Neuropsychopharmacol 29, 158-170. doi:10.1038/sj.npp.1300310

Haney, M., Malcolm, R. J., Babalonis, S., Nuzzo, P. A., Cooper, Z. D., Bedi, G., et al. (2016). Oral Cannabidiol Does Not Alter the Subjective, Reinforcing or Cardiovascular Effects of Smoked Cannabis. Neuropsychopharmacol 41, 1974-1982. doi:10.1038/npp.2015.367

Hasin, D. S., Kerridge, B. T., Saha, T. D., Huang, B., Pickering, R., Smith, S. M., et al. (2016). Prevalence and Correlates of DSM-5 Cannabis Use Disorder, 20122013: Findings from the National Epidemiologic Survey on Alcohol and Related Conditions-III. Ajp 173, 588-599. doi:10.1176/appi.ajp.2015.15070907

Hay, G. L., Baracz, S. J., Everett, N. A., Roberts, J., Costa, P. A., Arnold, J. C., et al. (2018). Cannabidiol Treatment Reduces the Motivation to Self-Administer Methamphetamine and Methamphetamine-Primed Relapse in Rats. J. Psychopharmacol. 32, 1369-1378. doi:10.1177/0269881118799954

Heinsbroek, J. A., De Vries, T. J., and Peters, J. (2020). Glutamatergic Systems and Memory Mechanisms Underlying Opioid Addiction. Cold Spring Harb Perspect. Med. 11, a039602. doi:10.1101/cshperspect.a039602

Hindocha, C., Freeman, T. P., Grabski, M., Crudgington, H., Davies, A. C., Stroud, J. B., et al. (2018a). The Effects of Cannabidiol on Impulsivity and Memory during Abstinence in Cigarette Dependent Smokers. Sci. Rep. 8, 7568. doi:10. 1038/s41598-018-25846-2

Hindocha, C., Freeman, T. P., Grabski, M., Stroud, J. B., Crudgington, H., Davies, A. C., et al. (2018b). Cannabidiol Reverses Attentional Bias to Cigarette Cues in a Human Experimental Model of Tobacco Withdrawal. Addiction 113, 1696-1705. doi:10.1111/add.14243

Hine, B., Torrelio, M., and Gershon, S. (1975). Interactions between Cannabidiol and $\triangle 9$-THC during Abstinence in Morphine-dependent Rats. Life Sci. 17, 851-857. doi:10.1016/0024-3205(75)90435-x

Hser, Y.-I., Evans, E., Grella, C., Ling, W., and Anglin, D. (2015). Long-term Course of Opioid Addiction. Harv. Rev. Psychiatry 23, 76-89. doi:10.1097/hrp. 0000000000000052

Hser, Y.-I., Saxon, A. J., Huang, D., Hasson, A., Thomas, C., Hillhouse, M., et al. (2014). Treatment Retention Among Patients Randomized to Buprenorphine/ naloxone Compared to Methadone in a Multi-Site Trial. Addiction 109, 79-87. doi:10.1111/add.12333

Hudson, R., Renard, J., Norris, C., Rushlow, W. J., and Laviolette, S. R. (2019). Cannabidiol Counteracts the Psychotropic Side-Effects of $\Delta-9$ Tetrahydrocannabinol in the Ventral Hippocampus through Bidirectional Control of ERK1-2 Phosphorylation. J. Neurosci. 39, 8762-8777. doi:10. 1523/jneurosci.0708-19.2019

Hurd, Y. L., Spriggs, S., Alishayev, J., Winkel, G., Gurgov, K., Kudrich, C., et al. (2019). Cannabidiol for the Reduction of Cue-Induced Craving and Anxiety in Drug-Abstinent Individuals with Heroin Use Disorder: A Double-Blind Randomized Placebo-Controlled Trial. Ajp 176, 911-922. doi:10.1176/appi. ajp.2019.18101191

Ibeas Bih, C., Chen, T., Nunn, A. V. W., Bazelot, M., Dallas, M., and Whalley, B. J. (2015). Molecular Targets of Cannabidiol in Neurological Disorders. Neurotherapeutics 12, 699-730. doi:10.1007/s13311-015-0377-3

Iffland, K., and Grotenhermen, F. (2017). An Update on Safety and Side Effects of Cannabidiol: A Review of Clinical Data and Relevant Animal Studies. Cannabis Cannabinoid Res. 2, 139-154. doi:10.1089/can.2016.0034

Izgelov, D., Davidson, E., Barasch, D., Regev, A., Domb, A. J., and Hoffman, A. (2020). Pharmacokinetic Investigation of Synthetic Cannabidiol Oral 
Formulations in Healthy Volunteers. Eur. J. Pharmaceutics Biopharmaceutics 154, 108-115. doi:10.1016/j.ejpb.2020.06.021

Johnson, S., and North, R. (1992). Opioids Excite Dopamine Neurons by Hyperpolarization of Local Interneurons. J. Neurosci. 12, 483-488. doi:10. 1523/jneurosci.12-02-00483.1992

Jones, E., and Vlachou, S. (2020). A Critical Review of the Role of the Cannabinoid Compounds Delta(9)-Tetrahydrocannabinol (Delta(9)-THC) and Cannabidiol (CBD) and Their Combination in Multiple Sclerosis Treatment. Molecules 25. doi:10.3390/molecules25214930

Karimi-Haghighi, S., Dargahi, L., and Haghparast, A. (2020). Cannabidiol Modulates the Expression of Neuroinflammatory Factors in Stress- and Drug-Induced Reinstatement of Methamphetamine in Extinguished Rats. Addict. Biol. 25, e12740. doi:10.1111/adb.12740

Karimi-Haghighi, S., and Haghparast, A. (2018). Cannabidiol Inhibits PrimingInduced Reinstatement of Methamphetamine in REM Sleep Deprived Rats. Prog. Neuro-Psychopharmacol. Biol. Psychiatry 82, 307-313. doi:10.1016/j. pnpbp.2017.08.022

Kathmann, M., Flau, K., Redmer, A., Tränkle, C., and Schlicker, E. (2006). Cannabidiol Is an Allosteric Modulator at Mu- and Delta-Opioid Receptors. Naunyn Schmied Arch. Pharmacol. 372, 354-361. doi:10.1007/s00210-0060033-x

Katona, I., and Freund, T. F. (2012). Multiple Functions of Endocannabinoid Signaling in the Brain. Annu. Rev. Neurosci. 35, 529-558. doi:10.1146/annurevneuro-062111-150420

Katsidoni, V., Anagnostou, I., and Panagis, G. (2013). Cannabidiol Inhibits the Reward-Facilitating Effect of Morphine: Involvement of 5-HT1Areceptors in the Dorsal Raphe Nucleus. Addict. Biol. 18, 286-296. doi:10.1111/j.1369-1600. 2012.00483.x

Kelaï, S., Renoir, T., Chouchana, L., Saurini, F., Hanoun, N., Hamon, M., et al. (2008). Chronic Voluntary Ethanol Intake Hypersensitizes 5HT1Aautoreceptors in C57BL/6J Mice. J. Neurochem. 107, 1660-1670. doi:10.1111/j.1471-4159.2008.05733.x

Kirshenbaum, A. P., Olsen, D. M., and Bickel, W. K. (2009). A Quantitative Review of the Ubiquitous Relapse Curve. J. Substance Abuse Treat. 36, 8-17. doi:10. 1016/j.jsat.2008.04.001

Koob, G. F., and Volkow, N. D. (2010). Neurocircuitry of Addiction. Neuropsychopharmacol 35, 217-238. doi:10.1038/npp.2009.110

Kozela, E., Lev, N., Kaushansky, N., Eilam, R., Rimmerman, N., Levy, R., et al. (2011). Cannabidiol Inhibits Pathogenic T Cells, Decreases Spinal Microglial Activation and Ameliorates Multiple Sclerosis-like Disease in C57BL/6 Mice. Br. J. Pharmacol. 163, 1507-1519. doi:10.1111/j.1476-5381. 2011.01379.x

Lannoy, S., Billieux, J., Dormal, V., and Maurage, P. (2019). Behavioral and Cerebral Impairments Associated with Binge Drinking in Youth: A Critical Review. Psychol. Belg. 59, 116-155. doi:10.5334/pb.476

Laprairie, R. B., Bagher, A. M., Kelly, M. E. M., and Denovan-Wright, E. M. (2015). Cannabidiol Is a Negative Allosteric Modulator of the Cannabinoid CB1 Receptor. Br. J. Pharmacol. 172, 4790-4805. doi:10.1111/bph.13250

Levin, K. H., Copersino, M. L., Heishman, S. J., Liu, F., Kelly, D. L., Boggs, D. L., et al. (2010). Cannabis Withdrawal Symptoms in Non-treatment-seeking Adult Cannabis Smokers. Drug and Alcohol Dependence 111, 120-127. doi:10.1016/j. drugalcdep.2010.04.010

Leweke, F. M., Mueller, J. K., Lange, B., and Rohleder, C. (2016). Therapeutic Potential of Cannabinoids in Psychosis. Biol. Psychiatry 79, 604-612. doi:10. 1016/j.biopsych.2015.11.018

Leweke, F. M., Piomelli, D., Pahlisch, F., Muhl, D., Gerth, C. W., Hoyer, C., et al. (2012). Cannabidiol Enhances Anandamide Signaling and Alleviates Psychotic Symptoms of Schizophrenia. Transl Psychiatry 2, e94. doi:10.1038/tp.2012.15

Li, X., Shorter, D., and Kosten, T. R. (2014). Buprenorphine in the Treatment of Opioid Addiction: Opportunities, Challenges and Strategies. Expert Opin. Pharmacother. 15, 2263-2275. doi:10.1517/14656566.2014.955469

Linge, R., Jiménez-Sánchez, L., Campa, L., Pilar-Cuéllar, F., Vidal, R., Pazos, A., et al. (2016). Cannabidiol Induces Rapid-Acting Antidepressant-like Effects and Enhances Cortical 5-HT/glutamate Neurotransmission: Role of 5-HT1A Receptors. Neuropharmacol. 103, 16-26. doi:10.1016/j.neuropharm.2015. 12.017

Lintzeris, N., Bhardwaj, A., Mills, L., Dunlop, A., Copeland, J., McGregor, I., et al. (2019). Replacement for Cannabis Dependence Study, Nabiximols for the
Treatment of Cannabis Dependence: A Randomized Clinical Trial. JAMA Intern. Med. 179, 1242-1253. doi:10.1001/jamainternmed.2019.1993

Liput, D. J., Hammell, D. C., Stinchcomb, A. L., and Nixon, K. (2013). Transdermal Delivery of Cannabidiol Attenuates Binge Alcohol-Induced Neurodegeneration in a Rodent Model of an Alcohol Use Disorder. Pharmacol. Biochem. Behav. 111, 120-127. doi:10.1016/j.pbb.2013.08.013

Long, L. E., Malone, D. T., and Taylor, D. A. (2006). Cannabidiol Reverses MK801-Induced Disruption of Prepulse Inhibition in Mice. Neuropsychopharmacol 31, 795-803. doi:10.1038/sj.npp.1300838

Luján, M. Á., Cantacorps, L., and Valverde, O. (2019). The Pharmacological Reduction of Hippocampal Neurogenesis Attenuates the Protective Effects of Cannabidiol on Cocaine Voluntary Intake. Addict. Biol. 25, e12778. doi:10.1111/adb.12778

Luján, M. Á., Castro-Zavala, A., Alegre-Zurano, L., and Valverde, O. (2018). Repeated Cannabidiol Treatment Reduces Cocaine Intake and Modulates Neural Proliferation and CB1R Expression in the Mouse hippocampus. Neuropharmacol. 143, 163-175. doi:10.1016/j.neuropharm.2018.09.043

Lujan, M. A., and Valverde, O. (2020). The Pro-neurogenic Effects of Cannabidiol and its Potential Therapeutic Implications in Psychiatric Disorders. Front. Behav. Neurosci. 14, 109. doi:10.3389/fnbeh.2020.00109

Mackie, K. (2005). Distribution of Cannabinoid Receptors in the Central and Peripheral Nervous System. Handb Exp. Pharmacol. 168, 299-325. doi:10.1007/ 3-540-26573-2_10

Mahmud, A., Gallant, S., Sedki, F., D'Cunha, T., and Shalev, U. (2017). Effects of an Acute Cannabidiol Treatment on Cocaine Self-Administration and CueInduced Cocaine Seeking in Male Rats. J. Psychopharmacol. 31, 96-104. doi:10.1177/0269881116667706

Maisto, S. A., Clifford, P. R., Stout, R. L., and Davis, C. M. (2006). Drinking in the Year after Treatment as a Predictor of Three-Year Drinking Outcomes. J. Stud. Alcohol. 67, 823-832. doi:10.15288/jsa.2006.67.823

Maldonado, R., Valverde, O., and Berrendero, F. (2006). Involvement of the Endocannabinoid System in Drug Addiction. Trends Neurosciences 29, 225-232. doi:10.1016/j.tins.2006.01.008

Mandyam, C. D., and Koob, G. F. (2012). The Addicted Brain Craves New Neurons: Putative Role for Adult-Born Progenitors in Promoting Recovery. Trends Neurosciences 35, 250-260. doi:10.1016/j.tins.2011.12.005

Manzanares, J., Cabañero, D., Puente, N., García-Gutiérrez, M. S., Grandes, P., and Maldonado, R. (2018). Role of the Endocannabinoid System in Drug Addiction. Biochem. Pharmacol. 157, 108-121. doi:10.1016/j.bcp.2018.09.013

Marco, E. M., Garcia-Gutierrez, M. S., Bermudez-Silva, F. J., Moreira, F. A., Guimaraes, F., Manzanares, J., et al. (2011). Endocannabinoid System and Psychiatry: in Search of a Neurobiological Basis for Detrimental and Potential Therapeutic Effects. Front. Behav. Neurosci. 5, 63. doi:10.3389/fnbeh.2011. 00063

Marco, E. M., and Laviola, G. (2012). The Endocannabinoid System in the Regulation of Emotions throughout Lifespan: a Discussion on Therapeutic Perspectives. J. Psychopharmacol. 26, 150-163. doi:10.1177/0269881111408459

Markos, J., Harris, H., Gul, W., ElSohly, M., and Sufka, K. (2018). Effects of Cannabidiol on Morphine Conditioned Place Preference in Mice. Planta Med. 84, 221-224. doi:10.1055/s-0043-117838

Martín-Moreno, A. M., Reigada, D., Ramírez, B. G., Mechoulam, R., Innamorato, N., Cuadrado, A., et al. (2011). Cannabidiol and Other Cannabinoids Reduce Microglial Activation In Vitro and In Vivo: Relevance to Alzheimer's Disease. Mol. Pharmacol. 79, 964-973. doi:10.1124/mol.111.071290

Martinez-Pinilla, E., Varani, K., Reyes-Resina, I., Angelats, E., Vincenzi, F., Ferreiro-Vera, C., et al. (2017). Binding and Signaling Studies Disclose a Potential Allosteric Site for Cannabidiol in Cannabinoid CB2 Receptors. Front. Pharmacol. 8, 744. doi:10.3389/fphar.2017.00744

Massi, P., Valenti, M., Vaccani, A., Gasperi, V., Perletti, G., Marras, E., et al. (2008). 5-Lipoxygenase and Anandamide Hydrolase (FAAH) Mediate the Antitumor Activity of Cannabidiol, a Non-psychoactive Cannabinoid. J. Neurochem. 104, 1091-1100. doi:10.1111/j.1471-4159.2007.05073.x

Mattick, R. P., Kimber, J., Breen, C., and Davoli, M. (2014). Buprenorphine Maintenance versus Placebo or Methadone Maintenance for Opioid Dependence. Cochrane Database Syst. Rev. 3, CD002207. doi:10.1002/ 14651858.CD002207.pub3

McPartland, J. M., Duncan, M., Di Marzo, V., and Pertwee, R. G. (2015). Are Cannabidiol and $\Delta 9$-tetrahydrocannabivarin Negative Modulators of the 
Endocannabinoid System? A Systematic Review. Br. J. Pharmacol. 172, 737-753. doi:10.1111/bph.12944

McPartland, J. M., and Russo, E. B. (2014). "Non-phytocannabinoid Constituents of Cannabis and Herbal Synergy," in Handbook of Cannabis. Editor R. G. Pertwee (Oxford, UK: Oxford University Press UK), 280-295. doi:10. 1093/acprof:oso/9780199662685.003.0015

Mechoulam, R. S., Shvo, Y., and Hashish, -I. (1963). The Structure of Cannabidiol. Tetrahedron 19, 6. doi:10.1016/0040-4020(63)85022-x

Millar, S. A., Stone, N. L., Yates, A. S., and O'Sullivan, S. E. (2018). A Systematic Review on the Pharmacokinetics of Cannabidiol in Humans. Front. Pharmacol. 9, 1365. doi:10.3389/fphar.2018.01365

Morales, P., Hurst, D. P., and Reggio, P. H. (2017). Molecular Targets of the Phytocannabinoids: A Complex Picture. Prog. Chem. Org. Nat. Prod. 103, 103-131. doi:10.1007/978-3-319-45541-9_4

Moreira, F. A., Aguiar, D. C., and Guimarães, F. S. (2006). Anxiolytic-like Effect of Cannabidiol in the Rat Vogel Conflict Test. Prog. Neuro-Psychopharmacol. Biol. Psychiatry 30, 1466-1471. doi:10.1016/j.pnpbp.2006.06.004

Moreira, F. A., and Guimarães, F. S. (2005). Cannabidiol Inhibits the Hyperlocomotion Induced by Psychotomimetic Drugs in Mice. Eur. J. Pharmacol. 512, 199-205. doi:10.1016/j.ejphar.2005.02.040

Morgan, C. J. A., and Curran, H. V. (2008). Effects of Cannabidiol on Schizophrenia-like Symptoms in People Who Use Cannabis. $B r$. J. Psychiatry 192, 306-307. doi:10.1192/bjp.bp.107.046649

Morgan, C. J. A., Das, R. K., Joye, A., Curran, H. V., and Kamboj, S. K. (2013). Cannabidiol Reduces Cigarette Consumption in Tobacco Smokers: Preliminary Findings. Addict. Behaviors 38, 2433-2436. doi:10.1016/j.addbeh.2013.03.011

Morgan, C. J. A., Gardener, C., Schafer, G., Swan, S., Demarchi, C., Freeman, T. P., et al. (2012). Sub-chronic Impact of Cannabinoids in Street Cannabis on Cognition, Psychotic-like Symptoms and Psychological Well-Being. Psychol. Med. 42, 391-400. doi:10.1017/s0033291711001322

Morgan, C. J. A., Schafer, G., Freeman, T. P., and Curran, H. V. (2010a). Impact of Cannabidiol on the Acute Memory and Psychotomimetic Effects of Smoked Cannabis: Naturalistic Study. Br. J. Psychiatry 197, 285-290. doi:10.1192/bjp.bp. 110.077503

Morgan, C. J., Freeman, T. P., Schafer, G. L., and Curran, H. V. (2010b). Cannabidiol Attenuates the Appetitive Effects of $\Delta 9$-Tetrahydrocannabinol in Humans Smoking Their Chosen Cannabis. Neuropsychopharmacol 35, 1879-1885. doi:10.1038/npp.2010.58

Müller, C. P., Carey, R. J., Huston, J. P., and De Souza Silva, M. A. (2007). Serotonin and Psychostimulant Addiction: Focus on 5-Htla-Receptors. Prog. Neurobiol. 81, 133-178. doi:10.1016/j.pneurobio.2007.01.001

Müller, C. P., and Homberg, J. R. (2015). The Role of Serotonin in Drug Use and Addiction. Behav. Brain Res. 277, 146-192. doi:10.1016/j.bbr.2014.04.007

Murillo-Rodríguez, E., Palomero-Rivero, M., Millán-Aldaco, D., Mechoulam, R., and Drucker-Colín, R. (2011). Effects on Sleep and Dopamine Levels of Microdialysis Perfusion of Cannabidiol into the Lateral Hypothalamus of Rats. Life Sci. 88, 504-511. doi:10.1016/j.lfs.2011.01.013

Myers, A. M., Siegele, P. B., Foss, J. D., Tuma, R. F., and Ward, S. J. (2019). Single and Combined Effects of Plant-Derived and Synthetic Cannabinoids on Cognition and Cannabinoid-Associated Withdrawal Signs in Mice. Br. J. Pharmacol. 176, 1552-1567. doi:10.1111/bph.14147

Navarrete, F., Aracil-Fernández, A., and Manzanares, J. (2018). Cannabidiol Regulates Behavioural Alterations and Gene Expression Changes Induced by Spontaneous Cannabinoid Withdrawal. Br. J. Pharmacol. 175, 2676-2688. doi:10.1111/bph.14226

Navarrete, F., Garcia-Gutierrez, M. S., Jurado-Barba, R., Rubio, G., Gasparyan, A., Austrich-Olivares, A., et al. (2020). Endocannabinoid System Components as Potential Biomarkers in Psychiatry. Front. Psychiatry 11, 315. doi:10.3389/fpsyt. 2020.00315

Neuhofer, D., Spencer, S. M., Chioma, V. C., Beloate, L. N., Schwartz, D., and Kalivas, P. W. (2019). The Loss of NMDAR-dependent LTD Following Cannabinoid Self-Administration Is Restored by Positive Allosteric Modulation of CB1 Receptors. Addict. Biol. 25, e12843. doi:10.1111/adb.12843

Niesink, R. J., and van Laar, M. W. (2013). Does Cannabidiol Protect against Adverse Psychological Effects of THC?. Front. Psychiatry 4, 130. doi:10.3389/ fpsyt.2013.00130

Norris, C., Loureiro, M., Kramar, C., Zunder, J., Renard, J., Rushlow, W., et al. (2016). Cannabidiol Modulates Fear Memory Formation through Interactions with Serotonergic Transmission in the Mesolimbic System. Neuropsychopharmacol 41, 2839-2850. doi:10.1038/npp.2016.93

Nutt, D. J., Lingford-Hughes, A., Erritzoe, D., and Stokes, P. R. A. (2015). The Dopamine Theory of Addiction: 40 Years of Highs and Lows. Nat. Rev. Neurosci. 16, 305-312. doi:10.1038/nrn3939

Oms, O. M. d. 1. S. (2019). Informe sobre la situación mundial del alcohol y la salud 2018. Washington, D.C.: Resumen..

Osborne, A. L., Solowij, N., and Weston-Green, K. (2016). A Systematic Review of the Effect of Cannabidiol on Cognitive Function: Relevance to Schizophrenia. Neurosci. biobehavioral Rev. 72, 310-324. doi:10.1016/j.neubiorev.2016.11.012

Parker, L. A., Burton, P., Sorge, R. E., Yakiwchuk, C., and Mechoulam, R. (2004). Effect of Low Doses of ?9-tetrahydrocannabinol and Cannabidiol on the Extinction of Cocaine-Induced and Amphetamine-Induced Conditioned Place Preference Learning in Rats. Psychopharmacol. 175, 360-366. doi:10. 1007/s00213-004-1825-7

Parsons, L. H., and Hurd, Y. L. (2015). Endocannabinoid Signalling in Reward and Addiction. Nat. Rev. Neurosci. 16, 579-594. doi:10.1038/nrn4004

Pasareanu, A. R., Vederhus, J. K., Opsal, A., Kristensen, O., and Clausen, T. (2016). Improved Drug-Use Patterns at 6 Months Post-discharge from Inpatient Substance Use Disorder Treatment: Results from Compulsorily and Voluntarily Admitted Patients. BMC Health Serv. Res. 16, 291. doi:10.1186/ s12913-016-1548-6

Patel, J., and Marwaha, R. (2020). Cannabis Use Disorder, StatPearls. Treasure Island (FL).

Patti, F., Messina, S., Solaro, C., Amato, M. P., Bergamaschi, R., Bonavita, S., et al. (2016). Efficacy and Safety of Cannabinoid Oromucosal Spray for Multiple Sclerosis Spasticity. J. Neurol. Neurosurg. Psychiatry 87, 944-951. doi:10.1136/ jnnp-2015-312591

Peres, F. F., Levin, R., Almeida, V., Zuardi, A. W., Hallak, J. E., Crippa, J. A., et al. (2016). Cannabidiol, Among Other Cannabinoid Drugs, Modulates Prepulse Inhibition of Startle in the SHR Animal Model: Implications for Schizophrenia Pharmacotherapy. Front. Pharmacol. 7, 303. doi:10.3389/ fphar.2016.00303

Pertwee, R. G. (2008). The Diverse CB1 and CB2 Receptor Pharmacology of Three Plant Cannabinoids: $\Delta 9$-tetrahydrocannabinol, Cannabidiol and $\Delta 9$ -tetrahydrocannabivarin. Br. J. Pharmacol. 153, 199-215. doi:10.1038/sj.bjp. 0707442

Perucca, E., and Bialer, M. (2020). Critical Aspects Affecting Cannabidiol Oral Bioavailability and Metabolic Elimination, and Related Clinical Implications. CNS Drugs 34, 795-800. doi:10.1007/s40263-020-00741-5

Pinto, E., Reggers, J., Pitchot, W., Hansenne, M., Fuchs, S., and Ansseau, M. (2002). Neuroendocrine Evaluation of 5-HT1A Function in Male Alcoholic Patients. Psychoneuroendocrinol. 27, 873-879. doi:10.1016/s0306-4530(01)00088-9

Piomelli, D. (2003). The Molecular Logic of Endocannabinoid Signalling. Nat. Rev. Neurosci. 4, 873-884. doi:10.1038/nrn1247

Prieto, J. P., López Hill, X., Urbanavicius, J., Sanchez, V., Nadal, X., and Scorza, C. (2020). Cannabidiol Prevents the Expression of the Locomotor Sensitization and the Metabolic Changes in the Nucleus Accumbens and Prefrontal Cortex Elicited by the Combined Administration of Cocaine and Caffeine in Rats. Neurotox Res. 38, 478-486. doi:10.1007/s12640-020-00218-9

Raucci, U., Pietrafusa, N., Paolino, M. C., Di Nardo, G., Villa, M. P., Pavone, P., et al. (2020). Cannabidiol Treatment for Refractory Epilepsies in Pediatrics. Front. Pharmacol. 11, 586110. doi:10.3389/fphar.2020.586110

Razavi, Y., Shabani, R., Mehdizadeh, M., and Haghparast, A. (2020). Neuroprotective Effect of Chronic Administration of Cannabidiol during the Abstinence Period on Methamphetamine-Induced Impairment of Recognition Memory in the Rats. Behav. Pharmacol. 31, 385-396. doi:10. 1097/fbp.0000000000000544

Ren, Y., Whittard, J., Higuera-Matas, A., Morris, C. V., and Hurd, Y. L. (2009). Cannabidiol, a Nonpsychotropic Component of Cannabis, Inhibits CueInduced Heroin Seeking and Normalizes Discrete Mesolimbic Neuronal Disturbances. J. Neurosci. 29, 14764-14769. doi:10.1523/jneurosci.4291-09. 2009

Renard, J., Loureiro, M., Rosen, L. G., Zunder, J., de Oliveira, C., Schmid, S., et al. (2016). Cannabidiol Counteracts Amphetamine-Induced Neuronal and Behavioral Sensitization of the Mesolimbic Dopamine Pathway through a Novel mTOR/p70S6 Kinase Signaling Pathway. J. Neurosci. 36, 5160-5169. doi:10.1523/jneurosci.3387-15.2016 
Resstel, L. B. M., Joca, S. R. L., Moreira, F. A., Corrêa, F. M. A., and Guimarães, F. S. (2006). Effects of Cannabidiol and Diazepam on Behavioral and Cardiovascular Responses Induced by Contextual Conditioned Fear in Rats. Behav. Brain Res. 172, 294-298. doi:10.1016/j.bbr.2006.05.016

Risinger, F. O., and Boyce, J. M. (2002). 5-HT1A Receptor Blockade and the Motivational Profile of Ethanol. Life Sci. 71, 707-715. doi:10.1016/s00243205(02)01728-9

Robson, P. (2011). Abuse Potential and Psychoactive Effects of $\delta$-9tetrahydrocannabinol and Cannabidiol Oromucosal Spray (Sativex), a New Cannabinoid Medicine. Expert Opin. Drug Saf. 10, 675-685. doi:10.1517/ 14740338.2011.575778

Rolland, B., and Naassila, M. (2017). Binge Drinking: Current Diagnostic and Therapeutic Issues. CNS Drugs 31, 181-186. doi:10.1007/s40263-017-0413-4

Ronsley, C., Nolan, S., Knight, R., Hayashi, K., Klimas, J., Walley, A., et al. (2020). Treatment of Stimulant Use Disorder: A Systematic Review of Reviews. PLoS One 15, e0234809. doi:10.1371/journal.pone.0234809

Rudd, R. A., Seth, P., David, F., and Scholl, L. (2016). Increases in Drug and OpioidInvolved Overdose Deaths - United States, 2010-2015. MMWR Morb. Mortal. Wkly. Rep. 65, 1445-1452. doi:10.15585/mmwr.mm655051e1

Russo, E. B., Burnett, A., Hall, B., and Parker, K. K. (2005). Agonistic Properties of Cannabidiol at 5-HT1a Receptors. Neurochem. Res. 30, 1037-1043. doi:10. 1007/s11064-005-6978-1

Russo, E., and Guy, G. W. (2006). A Tale of Two Cannabinoids: the Therapeutic Rationale for Combining Tetrahydrocannabinol and Cannabidiol. Med. Hypotheses 66, 234-246. doi:10.1016/j.mehy.2005.08.026

Ryberg, E., Larsson, N., Sjögren, S., Hjorth, S., Hermansson, N.-O., Leonova, J., et al. (2007). The Orphan Receptor GPR55 Is a Novel Cannabinoid Receptor. Br. J. Pharmacol. 152, 1092-1101. doi:10.1038/sj.bjp.0707460

Sabioni, P., and Le Foll, B. (2019). Psychosocial and Pharmacological Interventions for the Treatment of Cannabis Use Disorder. Foc 17, 163-168. doi:10.1176/appi.focus.17202

Saravia, R., Ten-Blanco, M., Grande, M. T., Maldonado, R., and Berrendero, F. (2019). Anti-inflammatory Agents for Smoking Cessation? Focus on Cognitive Deficits Associated with Nicotine Withdrawal in Male Mice. Brain Behav. Immun. 75, 228-239. doi:10.1016/j.bbi.2018.11.003

Sartim, A. G., Guimarães, F. S., and Joca, S. R. L. (2016). Antidepressant-like Effect of Cannabidiol Injection into the Ventral Medial Prefrontal Cortex-Possible Involvement of 5-HT1A and CB1 Receptors. Behav. Brain Res. 303, 218-227. doi:10.1016/j.bbr.2016.01.033

Schiavon, A. P., Bonato, J. M., Milani, H., Guimarães, F. S., and Weffort de Oliveira, R. M. (2016). Influence of Single and Repeated Cannabidiol Administration on Emotional Behavior and Markers of Cell Proliferation and Neurogenesis in Non-stressed Mice. Prog. Neuro-Psychopharmacol. Biol. Psychiatry 64, 27-34. doi:10.1016/j.pnpbp.2015.06.017

Schoedel, K. A., Chen, N., Hilliard, A., White, L., Stott, C., Russo, E., et al. (2011). A Randomized, Double-Blind, Placebo-Controlled, Crossover Study to Evaluate the Subjective Abuse Potential and Cognitive Effects of Nabiximols Oromucosal Spray in Subjects with a History of Recreational Cannabis Use. Hum. Psychopharmacol. 26, 224-236. doi:10.1002/hup.1196

Schoedel, K. A., Szeto, I., Setnik, B., Sellers, E. M., Levy-Cooperman, N., Mills, C., et al. (2018). Abuse Potential Assessment of Cannabidiol (CBD) in Recreational Polydrug Users: A Randomized, Double-Blind, Controlled Trial. Epilepsy Behav. 88, 162-171. doi:10.1016/j.yebeh.2018.07.027

Seeman, P. (2016). Cannabidiol Is a Partial Agonist at Dopamine D2High Receptors, Predicting its Antipsychotic Clinical Dose. Transl Psychiatry 6, e920. doi:10.1038/tp.2016.195

Sekar, K., and Pack, A. (2019). Epidiolex as Adjunct Therapy for Treatment of Refractory Epilepsy: a Comprehensive Review with a Focus on Adverse Effects. F1000Res 8, F1000Res. doi:10.12688/f1000research.16515.18

Shannon, S., and Opila-Lehman, J. (2015). Cannabidiol Oil for Decreasing Addictive Use of Marijuana: A Case Report. Integr. Med. (Encinitas) 14, 31-35.

Sharir, H., and Abood, M. E. (2010). Pharmacological Characterization of GPR55, a Putative Cannabinoid Receptor. Pharmacol. Ther. 126, 301-313. doi:10.1016/j. pharmthera.2010.02.004

Sinha, R. (2011). New Findings on Biological Factors Predicting Addiction Relapse Vulnerability. Curr. Psychiatry Rep. 13, 398-405. doi:10.1007/s11920-0110224-0

Sloan, M. E., Gowin, J. L., Ramchandani, V. A., Hurd, Y. L., and Le Foll, B. (2017). The Endocannabinoid System as a Target for Addiction Treatment: Trials and
Tribulations. Neuropharmacol. 124, 73-83. doi:10.1016/j.neuropharm.2017. 05.031

Solinas, M., Goldberg, S. R., and Piomelli, D. (2008). The Endocannabinoid System in Brain Reward Processes. Br. J. Pharmacol. 154, 369-383. doi:10.1038/bjp. 2008.130

Solowij, N., Broyd, S., Greenwood, L.-m., van Hell, H., Martelozzo, D., Rueb, K., et al. (2019). A Randomised Controlled Trial of Vaporised 49 tetrahydrocannabinol and Cannabidiol Alone and in Combination in Frequent and Infrequent Cannabis Users: Acute Intoxication Effects. Eur. Arch. Psychiatry Clin. Neurosci. 269, 17-35. doi:10.1007/s00406-019-00978-2

Solowij, N., Broyd, S. J., Beale, C., Prick, J.-A., Greenwood, L.-m., van Hell, H., et al. (2018). Therapeutic Effects of Prolonged Cannabidiol Treatment on Psychological Symptoms and Cognitive Function in Regular Cannabis Users: A Pragmatic Open-Label Clinical Trial. Cannabis Cannabinoid Res. 3, 21-34. doi:10.1089/can.2017.0043

Soyka, M., and Müller, C. A. (2017). Pharmacotherapy of Alcoholism - an Update on Approved and Off-Label Medications. Expert Opin. Pharmacother. 18, 1187-1199. doi:10.1080/14656566.2017.1349098

Spanagel, R., Herz, A., and Shippenberg, T. S. (1992). Opposing Tonically Active Endogenous Opioid Systems Modulate the Mesolimbic Dopaminergic Pathway. Proc. Natl. Acad. Sci. 89, 2046-2050. doi:10. 1073/pnas.89.6.2046

Stark, T., Di Bartolomeo, M., Di Marco, R., Drazanova, E., Platania, C. B. M., Iannotti, F. A., et al. (2020). Altered Dopamine D3 Receptor Gene Expression in MAM Model of Schizophrenia Is Reversed by Peripubertal Cannabidiol Treatment. Biochem. Pharmacol. 177, 114004. doi:10.1016/j.bcp.2020.114004

Substance Abuse and Mental Health Services Administration (2016). National Survey on Drug Use and Health. Rockville, MD: Detailed Tables.

Taffe, M. A., Kotzebue, R. W., Crean, R. D., Crawford, E. F., Edwards, S., and Mandyam, C. D. (2010). Long-lasting Reduction in Hippocampal Neurogenesis by Alcohol Consumption in Adolescent Nonhuman Primates. Proc. Natl. Acad. Sci. 107, 11104-11109. doi:10.1073/pnas.0912810107

Tanda, G., and Di Chiara, G. (1998). A Dopamine-Mlopioid Link in the Rat Ventral Tegmentum Shared by Palatable Food (Fonzies) and Nonpsychostimulant Drugs of Abuse. Eur. J. Neurosci. 10, 1179-1187. doi:10. 1046/j.1460-9568.1998.00135.x

Taylor, L., Gidal, B., Blakey, G., Tayo, B., and Morrison, G. (2018). A Phase I, Randomized, Double-Blind, Placebo-Controlled, Single Ascending Dose, Multiple Dose, and Food Effect Trial of the Safety, Tolerability and Pharmacokinetics of Highly Purified Cannabidiol in Healthy Subjects. CNS Drugs 32, 1053-1067. doi:10.1007/s40263-018-0578-5

Tham, M., Yilmaz, O., Alaverdashvili, M., Kelly, M. E. M., Denovan-Wright, E. M., and Laprairie, R. B. (2019). Allosteric and Orthosteric Pharmacology of Cannabidiol and Cannabidiol-Dimethylheptyl at the Type 1 and Type 2 Cannabinoid Receptors. Br. J. Pharmacol. 176, 1455-1469. doi:10.1111/bph. 14440

Thomas, A., Baillie, G. L., Phillips, A. M., Razdan, R. K., Ross, R. A., and Pertwee, R. G. (2007). Cannabidiol Displays Unexpectedly High Potency as an Antagonist of CB1 and CB2 Receptor Agonists In Vitro. Br. J. Pharmacol. 150, 613-623. doi:10.1038/sj.bjp.0707133

Trifilieff, P., Feng, B., Urizar, E., Winiger, V., Ward, R. D., Taylor, K. M., et al. (2013). Increasing Dopamine D2 Receptor Expression in the Adult Nucleus Accumbens Enhances Motivation. Mol. Psychiatry 18, 1025-1033. doi:10.1038/ mp. 2013.57

Trigo, J. M., Lagzdins, D., Rehm, J., Selby, P., Gamaleddin, I., Fischer, B., et al. (2016b). Effects of Fixed or Self-Titrated Dosages of Sativex on Cannabis Withdrawal and Cravings. Drug and Alcohol Dependence 161, 298-306. doi:10. 1016/j.drugalcdep.2016.02.020

Trigo, J. M., and Le Foll, B. (2017). "The Role of the Endocannabinoid System in Addiction," in The Endocannabinoid System. Genetics, Biochemistry, and Therapy. Editor Elsevier (Academic Press), 187-236. doi:10.1016/b978-0-12809666-6.00006-x

Trigo, J. M., Soliman, A., Quilty, L. C., Fischer, B., Rehm, J., Selby, P., et al. (2018). Nabiximols Combined with Motivational Enhancement/cognitive Behavioral Therapy for the Treatment of Cannabis Dependence: A Pilot Randomized Clinical Trial. PLoS One 13, e0190768. doi:10.1371/journal.pone.0190768

Trigo, J. M., Soliman, A., Staios, G., Quilty, L., Fischer, B., George, T. P., et al. (2016a). Sativex Associated with Behavioral-Relapse Prevention Strategy as 
Treatment for Cannabis Dependence. J. Addict. Med. 10, 274-279. doi:10.1097/ adm. 0000000000000229

Turna, J., Syan, S. K., Frey, B. N., Rush, B., Costello, M. J., Weiss, M., et al. (2019). Cannabidiol as a Novel Candidate Alcohol Use Disorder Pharmacotherapy: A Systematic Review. Alcohol. Clin. Exp. Re 43, 550-563. doi:10.1111/acer.13964 United Nations Office on Drugs and Crime (2019). World Drug Report 2019.

van Huijstee, A. N., and Mansvelder, H. D. (2014). Glutamatergic Synaptic Plasticity in the Mesocorticolimbic System in Addiction. Front Cel Neurosci 8, 466. doi:10.3389/fncel.2014.00466

Vandrey, R., Stitzer, M. L., Mintzer, M. Z., Huestis, M. A., Murray, J. A., and Lee, D. (2013). The Dose Effects of Short-Term Dronabinol (Oral THC) Maintenance in Daily Cannabis Users. Drug and Alcohol Dependence 128, 64-70. doi:10. 1016/j.drugalcdep.2012.08.001

Vann, R. E., Gamage, T. F., Warner, J. A., Marshall, E. M., Taylor, N. L., Martin, B. R., et al. (2008). Divergent Effects of Cannabidiol on the Discriminative Stimulus and Place Conditioning Effects of $\Delta 9$-tetrahydrocannabinol. Drug and Alcohol Dependence 94, 191-198. doi:10.1016/j.drugalcdep.2007.11.017

Viudez-Martínez, A., García-Gutiérrez, M. S., and Manzanares, J. (2020). Gender Differences in the Effects of Cannabidiol on Ethanol Binge Drinking in Mice. Addict. Biol. 25, e12765. doi:10.1111/adb.12765

Viudez-Martinez, A., Garcia-Gutierrez, M. S., Fraguas-Sanchez, A. I., TorresSuarez, A. I., and Manzanares, J. (2018b). Effects of Cannabidiol Plus Naltrexone on Motivation and Ethanol Consumption. Br. J. Pharmacol. 175, 3369-3378. doi:10.1111/bph.14380

Viudez-Martínez, A., García-Gutiérrez, M. S., Medrano-Relinque, J., Navarrón, C. M., Navarrete, F., and Manzanares, J. (2019). Cannabidiol Does Not Display Drug Abuse Potential in Mice Behavior. Acta Pharmacol. Sin 40, 358-364. doi:10.1038/s41401-018-0032-8

Viudez-Martínez, A., García-Gutiérrez, M. S., Navarrón, C. M., Morales-Calero, M. I., Navarrete, F., Torres-Suárez, A. I., et al. (2018a). Cannabidiol Reduces Ethanol Consumption, Motivation and Relapse in Mice. Addict. Biol. 23, 154-164. doi:10.1111/adb.12495

Wall, M. B., Pope, R., Freeman, T. P., Kowalczyk, O. S., Demetriou, L., Mokrysz, C., et al. (2019). Dissociable Effects of Cannabis with and without Cannabidiol on the Human Brain's Resting-State Functional Connectivity. J. Psychopharmacol. 33, 822-830. doi:10.1177/0269881119841568

Wang, Y., Mukhopadhyay, P., Cao, Z., Wang, H., Feng, D., Hasko, G., et al. (2017). Cannabidiol Attenuates Alcohol-Induced Liver Steatosis, Metabolic Dysregulation, Inflammation and Neutrophil-Mediated Injury. Sci. Rep. 7, 12064. doi:10.1038/s41598-017-10924-8

WHO (2018). Global Status Report on Alcohol and Health.

Wise, R. A. (2004). Dopamine, Learning and Motivation. Nat. Rev. Neurosci. 5, 483-494. doi:10.1038/nrn1406

Witkiewitz, K. (2011). Predictors of Heavy Drinking during and Following Treatment. Psychol. Addict. Behaviors 25, 426-438. doi:10.1037/a0022889

Wolf, S. A., Bick-Sander, A., Fabel, K., Leal-Galicia, P., Tauber, S., RamirezRodriguez, G., et al. (2010). Cannabinoid Receptor CB1 Mediates Baseline and Activity-Induced Survival of New Neurons in Adult Hippocampal Neurogenesis. Cell Commun Signal 8, 12. doi:10.1186/1478-811x-8-12

World Drug Report (2020). United Nation Office on Drugs and Crime (UNODC). World Health Organization (2018). International Classification of Diseases for Mortality and Morbidity Statistics (11th Revision). Retrieved from https://icd. who.int/browse11/1-m/en.
World Health Organization (Who) (2020). Tobacco Fact Sheet. URL https://www. who.int/news-room/fact-sheets/detail/tobacco.

Wright, M. J., Jr., Vandewater, S. A., and Taffe, M. A. (2013). Cannabidiol Attenuates Deficits of Visuospatial Associative Memory Induced by $\Delta 9$ tetrahydrocannabinol. Br. J. Pharmacol. 170, 1365-1373. doi:10.1111/bph.12199

Yamaguchi, T., Wang, H.-L., Li, X., Ng, T. H., and Morales, M. (2011). Mesocorticolimbic Glutamatergic Pathway. J. Neurosci. 31, 8476-8490. doi:10.1523/jneurosci.1598-11.2011

Yang, G., Liu, L., Zhang, R., Li, J., Leung, C.-K., Huang, J., et al. (2020). Cannabidiol Attenuates Methamphetamine-Induced Conditioned Place Preference via the Sigma1R/AKT/GSK-3ß/CREB Signaling Pathway in Rats. Toxicol. Res. (Camb) 9, 202-211. doi:10.1093/toxres/tfaa021

Yang, L., Rozenfeld, R., Wu, D., Devi, L. A., Zhang, Z., and Cederbaum, A. (2014). Cannabidiol Protects Liver from Binge Alcohol-Induced Steatosis by Mechanisms Including Inhibition of Oxidative Stress and Increase in Autophagy. Free Radic. Biol. Med. 68, 260-267. doi:10.1016/j.freeradbiomed. 2013.12.026

You, I.-J., Wright, S. R., Garcia-Garcia, A. L., Tapper, A. R., Gardner, P. D., Koob, G. F., et al. (2016). 5-HT1A Autoreceptors in the Dorsal Raphe Nucleus Convey Vulnerability to Compulsive Cocaine Seeking. Neuropsychopharmacol 41, 1210-1222. doi:10.1038/npp.2015.268

Zanelati, T., Biojone, C., Moreira, F., Guimarães, F., and Joca, S. (2010). Antidepressant-like Effects of Cannabidiol in Mice: Possible Involvement of 5-HT1A Receptors. Br. J. Pharmacol. 159, 122-128. doi:10.1111/j.1476-5381. 2009.00521.x

Zhang, P.-W., Ishiguro, H., Ohtsuki, T., Hess, J., Carillo, F., Walther, D., et al. (2004). Human Cannabinoid Receptor 1: $5^{\prime}$ Exons, Candidate Regulatory Regions, Polymorphisms, Haplotypes and Association with Polysubstance Abuse. Mol. Psychiatry 9, 916-931. doi:10.1038/sj.mp.4001560

Zou, S., and Kumar, U. (2018). Cannabinoid Receptors and the Endocannabinoid System: Signaling and Function in the Central Nervous System. Int. J. Mol. Sci. 19. doi:10.3390/ijms19030833

Zuardi, A., Crippa, J., Hallak, J., Pinto, J., Chagas, M., Rodrigues, G., et al. (2009). Cannabidiol for the Treatment of Psychosis in Parkinson's Disease. J. Psychopharmacol. 23, 979-983. doi:10.1177/0269881108096519

Zuardi, A. W., Antunes Rodrigues, J., and Cunha, J. M. (1991). Effects of Cannabidiol in Animal Models Predictive of Antipsychotic Activity. Psychopharmacol. 104, 260-264. doi:10.1007/bf02244189

Zuardi, A. W., Shirakawa, I., Finkelfarb, E., and Karniol, I. G. (1982). Action of Cannabidiol on the Anxiety and Other Effects Produced by ?9-THC in Normal Subjects. Psychopharmacol. 76, 245-250. doi:10.1007/bf00432554

Conflict of Interest: The authors declare that the research was conducted in the absence of any commercial or financial relationships that could be construed as a potential conflict of interest.

Copyright (c) 2021 Navarrete, García-Gutiérrez, Gasparyan, Austrich-Olivares and Manzanares. This is an open-access article distributed under the terms of the Creative Commons Attribution License (CC BY). The use, distribution or reproduction in other forums is permitted, provided the original author(s) and the copyright owner(s) are credited and that the original publication in this journal is cited, in accordance with accepted academic practice. No use, distribution or reproduction is permitted which does not comply with these terms. 